\title{
Dynamics of slab tear faults: Insights from numerical modelling
}

\author{
Alina J. Hale ${ }^{\mathrm{a}, *}$, Klaus-D. Gottschaldt ${ }^{\mathrm{b}, 1}$, Gideon Rosenbaum ${ }^{\mathrm{c}}$, Laurent Bourgouin ${ }^{\mathrm{b}}$, \\ Matthieu Bauchy ${ }^{\text {b }}$, Hans Mühlhaus ${ }^{b}$ \\ a The School of Geosciences, The University of Sydney, Australia \\ ${ }^{\mathrm{b}}$ ESSCC, School of Earth Sciences, The University of Queensland, Australia \\ c School of Earth Sciences, The University of Queensland, Australia
}

\section{A R T I C L E I N F O}

\section{Article history:}

Received 22 January 2009

Received in revised form 1 May 2009

Accepted 20 May 2009

Available online 24 May 2009

\section{Keywords:}

Subduction

Tear resistance

Computational modeling

FEM

\begin{abstract}
A B S T R A C T
Tear resistance at the edge of a slab is an important parameter controlling the evolution of subduction zones. However, compared with other subduction parameters such as plate strength, plate viscosity, plate thickness and trench width, the dynamics of tearing are poorly understood. Here we obtain a first-order understanding of the dynamics and morphology of subduction zones to resistance during tear propagation, by developing and using a novel computational modelling technique for subducting slabs, with side boundaries described by visco-plastic weak zones, developing into tear faults. Our 3D model is based upon a visco-plastic slab that sinks into the less dense mantle, generating poloidal and toroidal flows. The asthenospheric mantle field is static and only develops flow due to the subducting slab. We use the finite element code eScript/Finley and the level set method to describe the lithosphere to solve this fluid dynamics problem. Our results show the importance of tear resistance for the speed of trench migration and for shaping the final geometry of subduction systems. We show that slab tearing along a weak layer can result in a relatively straight slab hinge shape, while increasing the strength in the weak layer results in the curvature of the hinge increasing substantially. High tear resistance at the slab edges may hinder rollback to the extent that the slab becomes stretched and recumbently folded at the base of the domain. Tear resistance also controls whether the subducting lithosphere can experience accelerating rollback velocities or a constant rollback velocity.
\end{abstract}

(C) 2009 Elsevier B.V. All rights reserved.

\section{Introduction}

The lifecycle of subduction zones typically involves subduction initiation, accelerated sinking of the slab tip through the upper mantle, interaction with the $660-\mathrm{km}$ discontinuity, and steady subduction until the arrival of buoyant lithosphere that prevents further subduction (Funiciello et al., 2003). During this lifecycle, most subduction hinges migrate with respect to the lower mantle, typically in a direction opposite to the dip of subduction (Garfunkel et al., 1986; Royden, 1993; Schellart, 2008; Schellart et al., 2008). This process, known as subduction rollback, is affected by the interaction of the slab with induced or background asthenospheric mantle flow (Dvorkin et al., 1993; Schellart, 2004a). Subduction rollback also plays a crucial role in the development of back-arc extensional basins, in particular when the velocity of subduction rollback exceeds the velocity of plate convergence (Dewey, 1980).

Uniform subduction rollback and its associated mantle flow are relatively well understood and has been simulated in numerous

\footnotetext{
* Corresponding author.

E-mail address: a.hale@usyd.edu.au (A.J. Hale).

${ }^{1}$ Now at: Deutsches Zentrum für Luft-und Raumfahrt, Institut für Physik der Atmosphäre, Oberpfaffenhofen, Germany.
}

experimental and numerical studies (Funiciello et al., 2003; Schellart, 2004a; Morra et al., 2006; Piromallo et al., 2006; Stegman et al., 2006; Schellart et al., 2007). However, much less is known about the dynamic response to non-uniform rollback velocities along the length of the subduction system. Such responses include the progressive curvature of subduction zones (e.g. Morra et al., 2006; Schellart et al., 2007) and the development of vertical slab tear faults (Govers and Wortel, 2005; Rosenbaum et al., 2008). The latter would propagate horizontally provided that subduction continues and the lithospheric strength is less than the slab strength. Otherwise subduction may stall or the slab may break off.

In this paper, we numerically model the evolution of a subducting slab with side boundaries controlled by tear faults. In published subduction models (e.g. Morra et al., 2006; Stegman et al., 2006; Schellart et al., 2007), tear resistance at the slab boundaries is implicitly neglected allowing free slab propagation. However, slab propagation is likely to be significantly affected by any resistance to tearing. The instantaneous lithospheric response to a subduction edge has been considered by Govers and Wortel (2005), however their models neglect the dynamics of trench migration and tear propagation. In the following models we address this issue, showing how tear resistance at a propagating fault affects trench migration and the geometry of subduction. 


\section{The mechanism of tear propagation}

Tear propagation in subducting slabs is dominated by shear stresses acting parallel to the fault plane and parallel to the crack front (similar to a Mode 3 Crack in fracture mechanics). The $\sigma_{z \theta}$ component of the stress tensor describes the shear stress acting on all planes that radiate from the crack front, where $Z$ is the axis perpendicular to the crack trace in plan-form view and $\theta$ is the polar angle measured from the projection of the crack trace ahead of the crack tip (Fig. 1). Propagation of a tear fault is facilitated through the failure of such planes, connected to the crack tip. Considering a half-infinite crack in an infinite 2D domain, the relevant component of the stress tensor near the tip is $\sigma_{z \theta} \propto R^{-0.5} \cos (\theta / 2)$, with $R$ being the distance from the tip (Zehnder, 2006). Since the maximum value of $\sigma_{z \theta}$ is immediately in front of the crack tip, the tear fault is most likely propagating parallel to the direction of subduction rollback, consistent with observations (Govers and Wortel, 2005; Rosenbaum et al., 2008).

The direction of tear propagation can be modified by more complex flow dynamics in the subduction system due to the interaction of rollback, tear resistance at the fault and induced mantle flow. Furthermore, the dependence of $\sigma_{z \theta}$ on $\theta$ is rather weak. Inhomogeneities may reduce the strength of the lithosphere near the crack front resulting in a weak zone and failure occurring away from the preferred propagation direction; a tear fault is likely to follow the path of least resistance in a direction generally in front of the propagating fault. Local changes to the propagation direction may ultimately affect the general direction of tear propagation, thereby changing the whole subduction zone. These weakest points could be along pre-existing faults (e.g. passive margins, Gurnis et al., 2000), weakened zones (e.g. back-arc basins), margins of strengthened lithosphere (e.g. seamount chains) or where mantle plumes impinge on the lithosphere. Mantle flow around edges of retreating slabs may itself produce volcanism that weakens the lithosphere at the tear fault (Govers and Wortel, 2005). The effective viscosity of vertically averaged continental lithosphere is estimated to be at least an order of magnitude smaller than that of oceanic lithosphere (Gordon, 2000). Since continental crust is more buoyant and unlikely to be subducted, tear faults are preferentially likely to propagate in the oceanic lithosphere, possibly along continental margins. Here we only consider tear faults in oceanic lithosphere.

\section{Methodology}

Our models aim to generate a first-order understanding of resistance to tear propagation on the dynamics and morphology of subduction zones. We use idealized numerical models to isolate the effects of tear resistance on a subducting slab. Subduction zones are localised features and therefore we neglect the sphericity of the Earth.

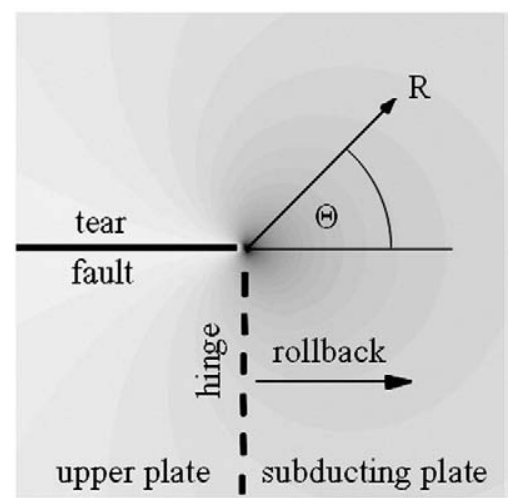

Fig. 1. Plan-view geometry of an idealized subduction zone edge. Grey contours show the variation of $\sigma_{z \theta}$ around the tip of the propagating tear fault (STEP), with darker shades corresponding to higher stress.
Subduction is modelled as fluid flow with infinite Prandtl number in a 3D Cartesian geometry with a dense oceanic lithosphere region sinking into less dense sublithospheric mantle. We do not consider an elasticity component in our simulations. This setup permits subduction rollback with tear propagation and induced mantle flow occurring naturally, driven by the negative buoyancy of the slab.

\subsection{Equation solved}

The dynamics of this system is governed by the conservation of mass in an incompressible medium;

$\nabla \cdot \vec{v}=0$

and conservation of momentum;

$\nabla \cdot \tau-\nabla P=\Delta \rho \vec{g}$

with the deviatoric stress tensor;

$\tau=\tau_{i j}=\eta\left(\frac{\partial v_{i}}{\partial x_{j}}+\frac{\partial v_{j}}{\partial x_{i}}\right)$

where velocity is $\vec{v}$, pressure is $P$, the lateral density variation is $\Delta \rho$, gravitational acceleration is $\vec{g}$ and dynamic viscosity is $\eta$. The density variations driving subduction are mainly due to cooling of the lithosphere. We impose an unstable density stratification as an initial condition. Although thermal diffusion is present in real subduction, it acts on a longer timescale than advection. Hence, we neglect the energy equation, because it is expected to have negligible effects on the density distribution over the duration ( $<50 \mathrm{Myr}$ ) of our numerical experiments.

We use a linear viscous rheology for the mantle. Parts of the lithosphere are viscous, while other parts are brittle. The brittle parts of the lithosphere can be modelled in the continuum limit by introducing a visco-plastic rheology with the non-linear effective viscosity (Moresi and Solomatov, 1998);

$\eta=\eta_{\text {creep }} \quad$ if $\quad \tau_{\text {creep }}<\tau_{\text {yield }}$

$\eta=\eta_{\text {yield }} \quad$ if $\quad \tau_{\text {creep }} \geq \tau_{\text {yield }}$

Viscous deformation occurs when the second invariant of the stress tensor $\tau_{\text {creep }}=2 \eta_{\text {creep }} \dot{\varepsilon}_{\text {II }}$ falls below the isotropic yield stress $\tau_{\text {yield, }}$, where $\dot{\varepsilon}_{I I}=\sqrt{\frac{1}{2} \dot{\varepsilon}_{i j} \dot{\varepsilon}_{i j}}$ is the second invariant of the strain rate tensor. When stresses reach $\tau_{\text {yield }}$ in the viscous mode, the effective viscosity is lowered in an iterative procedure to;

$\eta_{\text {yield }}=\frac{\tau_{\text {yield }}}{2 \dot{\varepsilon}_{I I}}$.

For our numerical simulations we vary the yield strength within a weak layer of the subducting slab.

\subsection{Numerical methods}

For the simulations presented in this paper we use the FEM software eScript and the FEM library Finley (Gross et al., 2007). We use a first-order element type with $20 \mathrm{~km}$ spacing. The Uzawa algorithm (a saddle-point algorithm) is used to solve the pressurevelocity field and we use a Courant condition to calculate the timestep $d t=0.3 \frac{h}{v_{\max }}$ for the displacement of the subducting lithosphere, where $h$ is the element spacing and $v_{\max }$ is the maximum velocity in the model domain.

We use the level set method to track the moving and deforming interface between the lithosphere and mantle. This method is based 
upon an implicit representation of the interface by a smooth function (Osher and Sethian, 1988). The function typically has the form of a signed distance to the interface, whereby the zero level curve or surface represents the actual interface between the fluids. The field equations are then solved on an Eulerian mesh with values for the parameters stored in tables, their value depending upon which side of the interface they are located. The distance function is updated during the simulation by solving the equation of motion using the velocity field calculated previously. The level set method is particularly well suited for two or three dimensional problems with strong topological changes such as breaking or merging as well as the formation of corners and cusps. The level set method as applied in this paper, using the velocity solution from an Uzawa algorithm, solves efficiently for large viscosity differences between slab and mantle, up to three orders of magnitude. But for larger viscosity differences the solution converges much more slowly. A more detailed description of our level set implementation is discussed in Hale et al., 2007.

The underlying FE library Finley is parallelized with OpenMP. We run our models on 8 CPUs of an SGI Altix ICE supercomputer at the Earth Systems Science Computational Centre at the University of Queensland, Australia. Typically, one simulation takes approximately 15 days to complete for the simulations presented in this paper. Our code was benchmarked against other subduction codes (OzBench et al., 2008). We also describe benchmarking of this technique for Stokes flow past a sphere in Appendix A.

\subsection{Model setup}

Our modelling domain is shown in Fig. 2, containing a lithospheric plate, with a subducting slab and the underlying upper mantle. The shear viscosity of the lower mantle is approximately 100 times higher than in the upper mantle (Steffen and Kaufmann, 2005). Since we are not interested in the detailed effects of phase boundaries or other possible mantle layering on subduction, we use a constant viscosity of $\eta_{\mathrm{UM}}=4 \times 10^{20} \mathrm{~Pa}$ s for the upper mantle (Mitrovica and Forte, 2004; Steffen and Kaufmann, 2005) and model an impermeable bottom for our model domain at a depth of $660 \mathrm{~km}$.

Subduction initiation (e.g. Regenauer-Lieb et al., 2001; Billen and Hirth, 2005) is beyond the scope of this paper. Hence, to start the process of subduction, the front end of the plate is bent at an angle $\theta=45^{\circ}$ and reaches a depth of $100 \mathrm{~km}$ below the base of the lithosphere. Our experiments span two stages, the free sinking of the slab tip through the upper mantle during incipient subduction, and interaction with the bottom of the lower mantle.

Since the model is symmetric about the vertical plane, through the centre of the slab, we model only half of the domain. The domain (Fig. 2) must be large enough to ensure that side walls do not affect the flow dynamics of the subducting slab. We use a total width of $1300 \mathrm{~km}$ in the $y$-axis, which includes a plate width of $600 \mathrm{~km}$, corresponding to $300 \mathrm{~km}$ in the model domain due to the reflected boundary. We solve one simulation with open (i.e. free-slip) boundary conditions to observe the velocity field at the domain boundaries; the rest of the simulations are solved with closed (i.e. fixed boundary conditions) boundaries (for minimum computational solving time). Observing identical simulations, except for open and closed boundary conditions, the results for all the parameters we have analysed are identical. Therefore, we can conclude that setting the boundary conditions at these walls to zero results in negligible difference in simulation results and hence the effects of the side walls on induced mantle flow is negligible.

We choose a box length that allows about the same amount of rollback for incipient and mature subduction. That is, a length in the $z$ axis of $3120 \mathrm{~km}$, with the tip and hinge of the slab initiated at distances of $1000 \mathrm{~km}$ and $1200 \mathrm{~km}$ from the edge of the domain, respectively. Gravity only permits vertical seafloor topography variations on the order of a few kilometres, hence we assume no vertical movement at the top of the box. However we use a free-slip top boundary condition for the $x$ and $y$-coordinates in the models. Yielding (Eq. (5)) results in a weak zone at the hinge that allows the slab to detach from the upper boundary.

\subsection{Model parameters}

We model the lithosphere as a plate of constant thickness $l_{\text {lith }}$, corresponding to a scenario where hinge rollback occurs at the same rate as thickening of the lithosphere due to cooling. The thickness of the lithosphere can be approximated from its age (Schubert et al., 2001). Sea floor ages near subduction zones vary from 5 to $156 \mathrm{Myr}$,

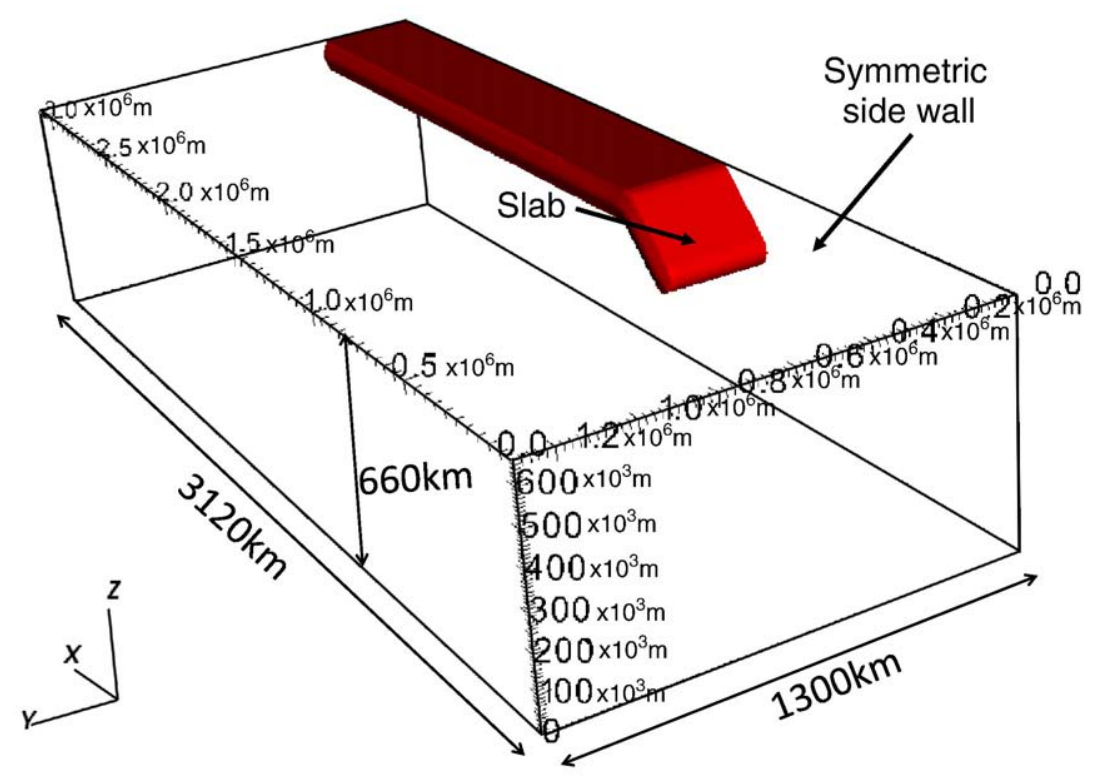

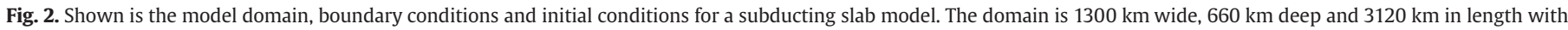

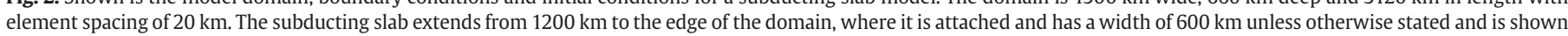
in red. The depth of the slab is $100 \mathrm{~km}$ for all simulations considered in this paper. Surrounding the slab is mantle material, shown as transparent in this diagram. 

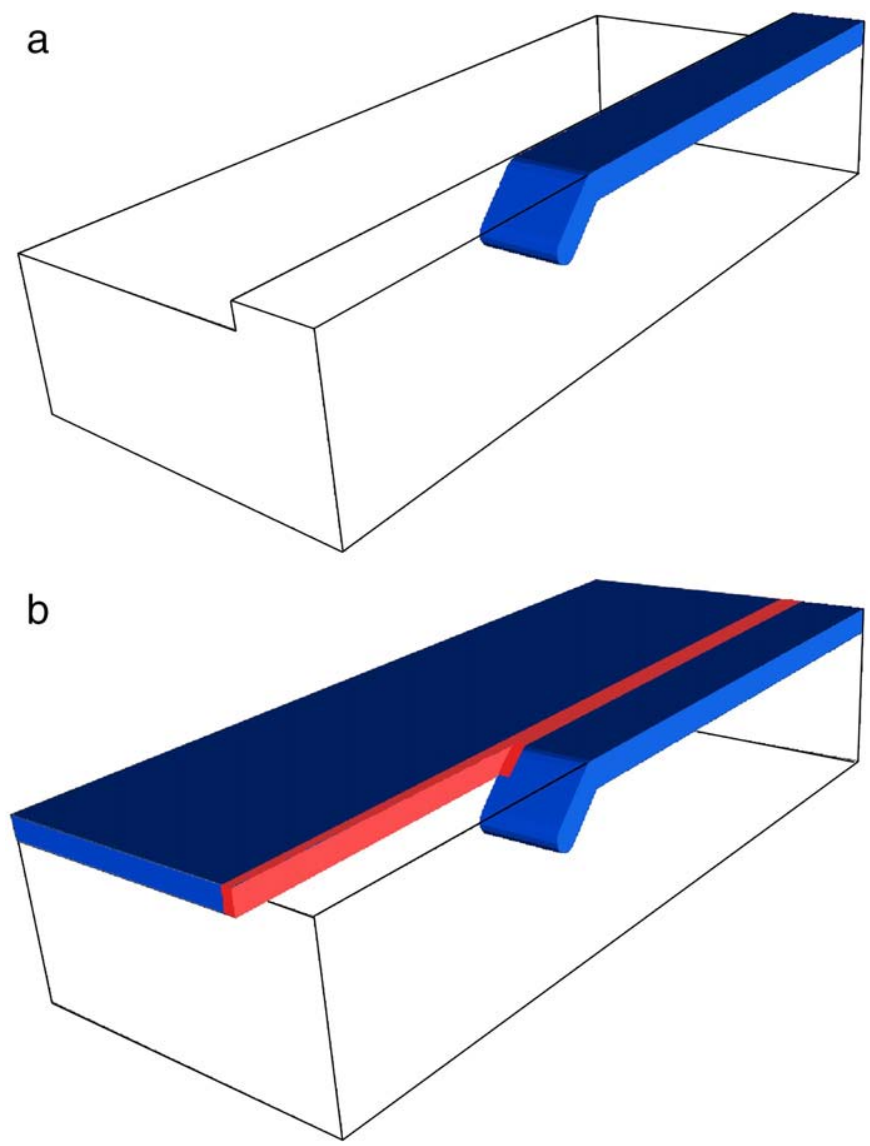

Fig. 3. Model domain initial conditions are shown for the two model meshes considered. For simulations with free-slip boundary conditions in the weak region mesh a) is used. For all simulations, except when free-slip boundary conditions are applied at the weak-boundary, the model domain b) is used. In Figure b) the weak region is shown by the red area. The subducting lithosphere is blue (shown as partly dipping), and in addition to this there is lithosphere with fixed boundary conditions on the other side of the weak region, which does not subduct. Note that in both figures mantle material surrounding the slab is shown as transparent.

with an average of $65 \mathrm{Myr}$ (Lallemand et al., 2005). This corresponds to $l_{\text {lith }}$ being between 30 and $125 \mathrm{~km}$, and using a lithosphere thickness of $100 \mathrm{~km}$ corresponds to a lithosphere age of approximately $65 \mathrm{Ma}$.

The density difference $\Delta \rho$ between lithospheric slab and upper mantle can be estimated from Airy compensation at different water depths at mid oceanic ridges before reaching a subduction trench. Sea floor depth for a $100 \mathrm{~km}$ thick lithospheric plate is approximately $5.5 \mathrm{~km}$ (Schubert et al., 2001), which translates into $\Delta \rho=69 \mathrm{~kg} \mathrm{~m}^{-3}$ (Royden and Husson, 2006). An independent estimate based on petrological and geophysical data suggests a lower depth-averaged density contrast of $\Delta \rho=40 \mathrm{~kg} \mathrm{~m}^{-3}$ between plate and adiabatic mantle (Afonso et al., 2007); however, we use the more established higher value.

The rheology is likely to be highly variable throughout the oceanic lithosphere. Elasticity plays a role near the surface (the upper 10$20 \mathrm{~km}$ ) forming faults by the process of brittle failure due to microphysical processes. Elasticity also serves to advect momentum, generating bending at shallow levels, and straightening of the slab at deeper levels. While flexural stresses on the non-subducting slab region contribute to the stress field near the subduction hinge. Below this depth deformation is most likely accommodated by distributed microcracks (i.e. a semi-brittle rheology, Kohlstedt et al., 1995) and lattice processes (i.e. semi-ductile rheology). Macroscopic plastic flow
Table 1

Parameters common to all models.

\begin{tabular}{lll}
\hline Parameter & Symbol & Value \\
\hline Gravitational acceleration & $g$ & $10 \mathrm{~m} \mathrm{~s}^{2}$ \\
Domain depth & $l_{z}$ & $660 \mathrm{~km}$ \\
Domain length & $l_{x}$ & $3120 \mathrm{~km}$ \\
Domain width & $l_{y}$ & $1300 \mathrm{~km}$ \\
Lithosphere thickness & $l_{\text {lith }}$ & $100 \mathrm{~km}$ \\
Initial length of lithosphere & $l_{\mathrm{s}}$ & $2000 \mathrm{~km}$ \\
Plate viscosity & $\eta_{\text {lith }}$ & $8 \times 10^{22} \mathrm{~Pa} \mathrm{~s}$ \\
Upper mantle viscosity & $\eta_{\mathrm{UM}}$ & $4 \times 10^{20} \mathrm{~Pa} \mathrm{~s}$ \\
Density of lithosphere & $\rho_{\text {lith }}$ & $3220 \mathrm{~kg} / \mathrm{m}^{3}$ \\
Density of upper mantle & $\rho_{\mathrm{UM}}$ & $3289 \mathrm{~kg} / \mathrm{m}^{3}$ \\
\hline
\end{tabular}

occurs when the pressure exceeds the plastic yield strength of the rocks (Tackley, 2000b) which can be modelled from a continuum mechanical perspective. This thermally activated viscous creep occurs at approximately $40 \mathrm{~km}$ depth, in medium age lithosphere (Kohlstedt et al., 1995). Elastic deformation on tear faults is in the order of kilometres (Govers and Wortel, 2005), with earthquakes and brittle deformation dissipating elastic energy on time scales of less than 1000 years. Since we are interested in time scales of $10^{5}-10^{7}$ years, where elastic deformation is small compared to plastic and viscous flow, the assumption of a visco-plastic lithospheric rheology (Eq. (4)) is appropriate for the time scales presented in this study.

An appropriate effective viscosity range for oceanic lithosphere, $\eta_{\text {lith }}$, has been constrained to be between $10^{22}$ and $10^{23} \mathrm{~Pa}$ s (Steinberger and Calderwood, 2006). Stegman et al. (2006) use an upper mantle shear viscosity, $\eta_{\mathrm{UM}}$, which is between 100 and 200 times smaller than the lithosphere shear viscosity. Hence, we use a shear upper mantle viscosity of $\eta_{\mathrm{UM}}=4 \times 10^{20} \mathrm{~Pa}$ s and an ocean lithosphere viscosity of $\eta_{\text {lith }}=8 \times 10^{22}$ Pa s. Higher effective viscosities are expected for the interior of plates (Steinberger and Calderwood, 2006), but lithospheric deformation is localized at the hinge in our model setup. Therefore we assign a constant value from within this weak range to the entire lithosphere and expect only limited further weakening by yielding.

Lithospheric strength in the brittle zone is determined by the frictional strength of faults, and is approximately proportional to pressure (Byerlee, 1968). In the semi-brittle/semi-ductile zone, the yield strength depends only weakly on pressure and decreases in the viscous lower lithosphere due to increasing temperature (Kohlstedt et al., 1995). To keep our models simple, we approximate this strength profile with a constant isotropic yield strength, $\tau_{\text {yield. }}$ The value for such an effective yield strength is undetermined but is likely to be in the range 1-1000 MPa (Kaus and Podladchikov, 2006). Large-scale tectonic systems are likely to have lower strengths than intact laboratory samples (with strengths of approximately $500 \mathrm{MPa}$ ) due

Table 2

Parameters that are varied. Since the model is symmetric at one side, only half of the subduction zone is modelled.

\begin{tabular}{llllll}
\hline Run & $\begin{array}{l}\tau_{\text {yield }} \\
{[\mathrm{MPa}]}\end{array}$ & $\begin{array}{l}\tau_{\text {yield }} \\
{[\mathrm{MPa}]}\end{array}$ & $\begin{array}{l}\Delta \rho \\
{\left[\mathrm{kg} \mathrm{m}^{-3}\right]}\end{array}$ & $\begin{array}{l}l_{\text {lith }} \\
{[\mathrm{km}]}\end{array}$ & $\begin{array}{l}l_{\text {slab }} \\
{[\mathrm{km}]}\end{array}$ \\
& Weak zone & Plate & Plate/mantle & Plate & Plate \\
\hline 0 & 0 & 100 & 69 & 100 & 600 \\
1 & 1 & 100 & 69 & 100 & 600 \\
2 & 5 & 100 & 69 & 100 & 600 \\
3 & 10 & 100 & 69 & 100 & 600 \\
4 & 25 & 100 & 69 & 100 & 600 \\
5 & 50 & 100 & 69 & 100 & 600 \\
6 & 75 & 100 & 69 & 100 & 600 \\
7 & 100 & 100 & 69 & 100 & 600 \\
8 & Fixed & 100 & 69 & 100 & 600 \\
9 & 25 & 100 & 69 & 100 & 400 \\
10 & 25 & 10 & 69 & 100 & 800 \\
11 & 5 & 10 & 40 & 100 & 600
\end{tabular}

$\tau_{\text {yield }}$ is the yield stress, $l_{\text {slab }}$ the width of the trench. 
to strain weakening or pre-existing faults (Tackley, 2000b). Furthermore, energy feedbacks, such as shear heating and thermal expansion, also play an important role in weakening the lithosphere (RegenauerLieb et al., 2006; Regenauer-Lieb et al., 2008). The lowest yield strength values, estimated to be around $10 \mathrm{MPa}$ from the stress release of earthquakes, describe the strength of the lithosphere with welldeveloped faults (Lachenbruch and Sass, 1991). Self-consistent models of plate tectonics (based on visco-plastic yielding) are successful for yield stresses in the order 100-150 MPa (Tackley, 2000a,b). This might be an appropriate approximation for the effective strength of oceanic lithosphere without well-developed faults.

We assign $\tau_{\text {yield }}=100 \mathrm{MPa}$ to our modelled lithosphere and we assign a tear region in our model domain along which slab tearing can occur (Fig. 3). The tear region is introduced along the path where tearing is most likely to occur, as discussed in Section 2. Fig. 3a shows the model domain used for $\tau_{\text {yield }}=0 \mathrm{MPa}$ (i.e. no tear resistance). For this specific simulation, it was necessary to define the free-slip edge as a boundary condition. Otherwise the viscosity would drop to zero for $\tau_{\text {yield }}=0 \mathrm{MPa}$ (Eq. (5)) in the weak zone, leading to a situation that our numerical model would be unable to solve. Fig. 3b shows the model domain used for simulations with $\tau_{\text {yield }}>0 \mathrm{MPa}$, with the weak region shown as red (corresponding to one element wide) and a fixed and deformable slab shown as blue. Both vertical, lithosphere cutting features approximate pre-existing weak zones. Other inhomogeneities of the subducting plate, like buoyant terranes or areas of higher strength, are not considered in this study.

Introducing these two model domains and boundary conditions allows us to address the two end-member states. That is, when the weak layer is entirely yielding $\left(\tau_{\text {yield }}=0 \mathrm{MPa}\right.$ ) versus when it is not (when fixed boundary conditions are used at the edge of the slab). Between these two end-member states there will be a combination of yielding and non-yielding regions of the weak layer as shown in our results.

We neglect the upper plate in our models since its influence is beyond the scope of this study, but it needs to be considered in the
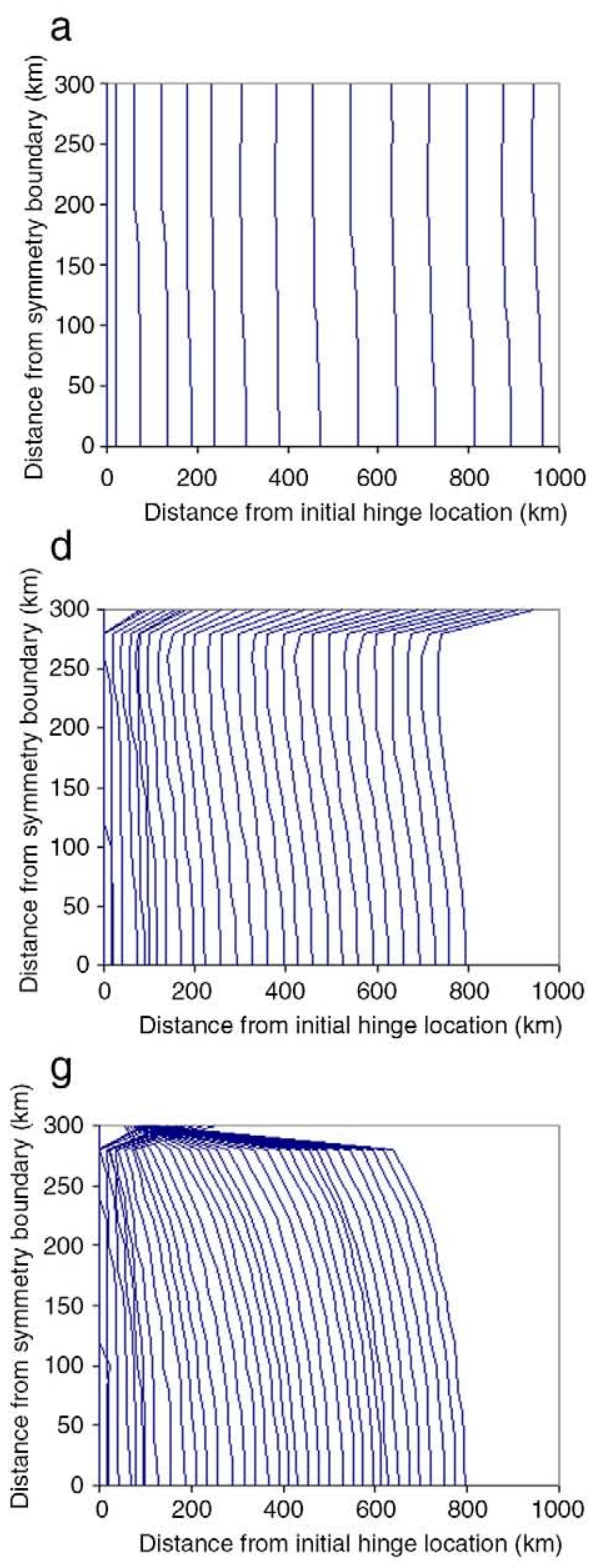
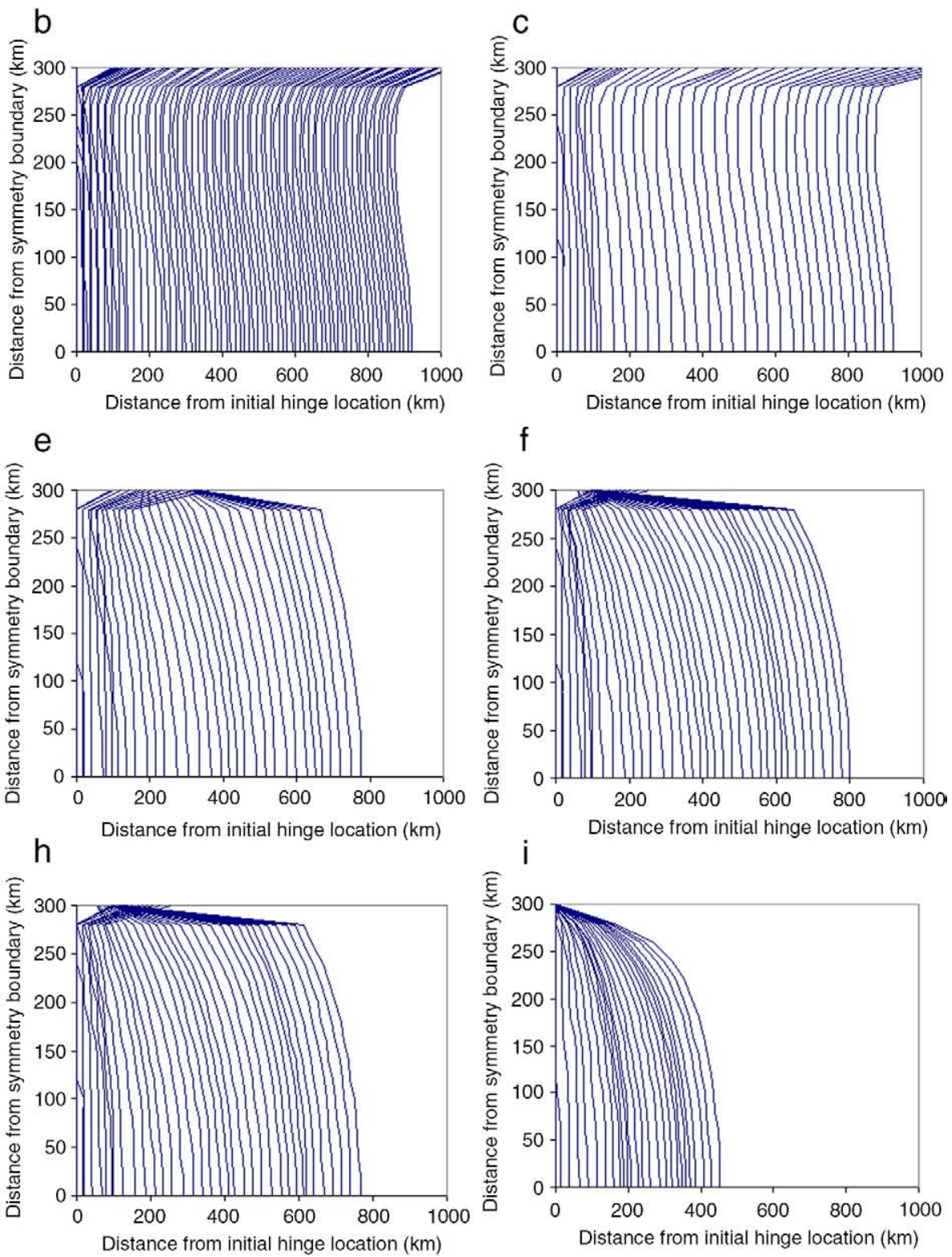

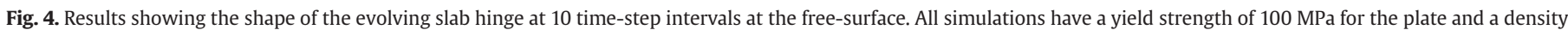

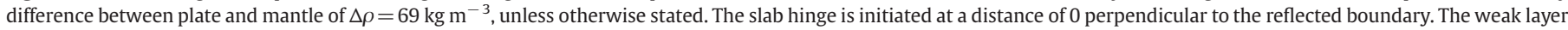

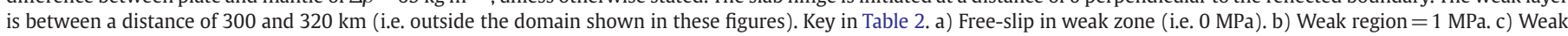

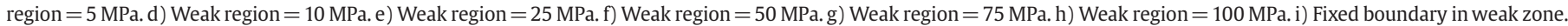


a

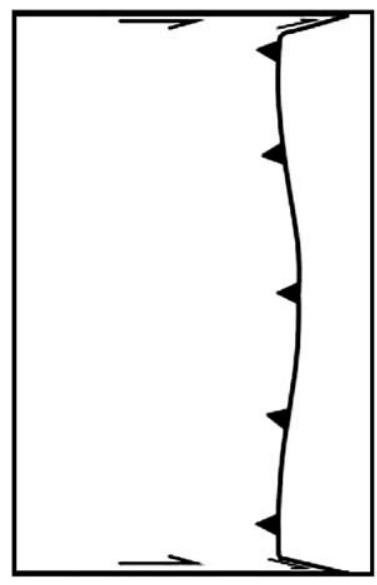

$\mathrm{b}$

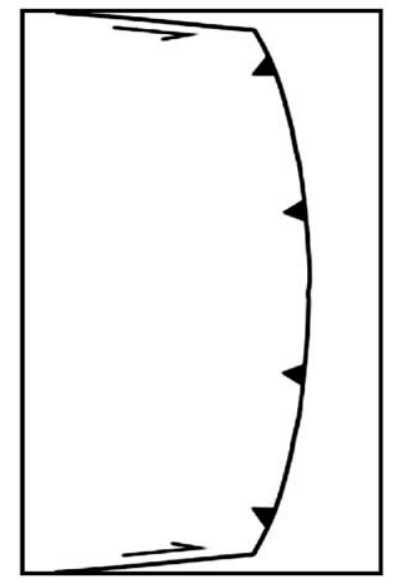

C

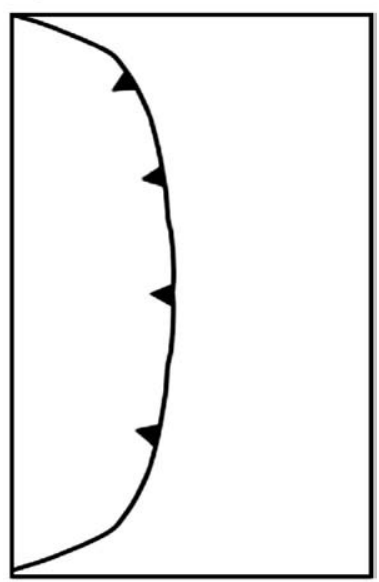

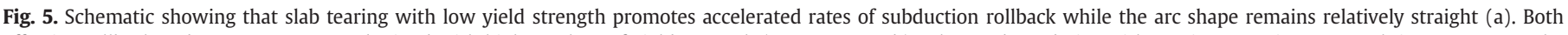

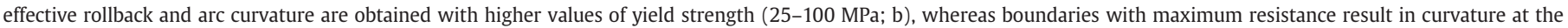
central slab segment but no tearing (c). The arrows correspond to region of tearing.

interpretation of our results. This simplification also makes it easier to isolate the effects of tearing at the edges of the subduction zone. Plate velocities are limited by the resistance of the mantle rather than by the frictional resistance at the trench (Moresi and Solomatov, 1998). Hence no special constitutive model is necessary for the decoupling zone, where upper and subducting plates interact.

Plate motion is determined by the integral of all forces acting on the plate. These include drag from the underlying mantle and forces of different magnitudes and directions from the different rim segments, i.e. convergent, divergent and transform boundaries. It is highly unlikely that a single subducting slab will determine the motion of the plate. Any particular subduction zone will instead generate a velocity between subducting plate and mantle. This velocity could be termed mantle wind in a plate-fixed reference system, or plate motion in a mantle-fixed system. Since our model contains only a part of one plate with a single subduction zone we fix the sides of the plate to the respective domain boundaries. Our setup deliberately neglects mantle wind, to better isolate the effects of tear resistance at the slab edges.

\subsection{Modelling strategy}

The parameter values that are maintained constant for all the simulations considered are listed in Table 1. Table 2 shows the combination of varied parameters for each simulation.

\section{Model results}

\subsection{Arc shape}

Model results showing the map-view shape of the subduction hinge are presented in Fig. 4. Results are shown at 10 time-step intervals and highlight the relative importance of mantle flow and tear resistance for shaping the subduction hinge. The length of each timestep is governed by the velocity field and typically ranges from 0.10 to 0.45 Ma.

Fig. 4a shows the shape of the slab hinge at the free-surface when using a free-slip boundary condition adjacent to the slab edge (i.e. a model set-up as described in Fig. 3a is used). The shape of the slab hinge is solely governed by the interaction with the induced mantle flow, since there is zero tear resistance. Under these conditions negligible arc curvature develops (Fig. 4a), in contrast with previous numerical results (e.g. Stegman et al., 2006). The reason for this discrepancy is because hinge curvature in the models of Stegman et al. (2006) are strongly affected by toroidal flow around the slab edge which extends to the free-surface of the domain, i.e. the slab is completely embedded in the mantle. In contrast, our model setup acts to suppress toroidal flow near the surface by imposing a no-slip boundary to a depth of $100 \mathrm{~km}$ below the domain free-surface in both sides of the subducting slab. Therefore, while our models are useful in quantifying slab deformation in response to tear resistance, they may underestimate additional deformation induced by toroidal flow. For comparison with previous studies (e.g. Stegman et al., 2006) we also simulate a subducting slab with a domain setup as described in Fig. 3b, but without the fixed plate or a weak layer region (see Appendix B). Then the slab edge is embedded into mantle material, which flows around the slab during rollback, initially producing a more prominent arc shape.

Our model with a free-slip tear zone (Fig. 4a) shows uniform rollback velocities along the hinge. However, results in Fig. 4b-d show that the largest rollback velocities occur close to the slab edge (280$300 \mathrm{~km}$ ). This is due to the very low yield strength values (1 MPa$10 \mathrm{MPa}$ ), and hence low viscosities, in the weak zone of these models (see Eq. (5)). Our models with a low yield strength weak layer impose no restrictions upon the movement of the slab edge into the less viscous mantle, other than the yield strength. Hence, the slab edge experiences less resistance to deformation in the $y$-direction, compared to other parts of the relatively stiff slab. This leads to preferential detachment and deformation in the weak zone, faster sinking at the edge and hence faster rollback.

Simulations that impose a higher yield strength in the weak zone (25 MPa-100 MPa, Fig. 4e-h) show an initial increase in rollback velocities close to the slab edge (similarly to Fig. $4 \mathrm{~b}-\mathrm{d}$ ) followed by deceleration and pinning of rollback velocities at the slab edge. This is a consequence of decreasing the slab pull forces and other negative buoyancy forces acting on the slab (e.g. Schellart, 2004b). The relative importance of yielding and tearing near the surface decreases as the slab volume in the mantle grows. This is due to both toroidal flow and slab stretching. Induced toroidal flow hinders rollback at the slab edge and pushes the slab back in the middle. Interaction with induced mantle flow becomes more important if a bigger slab area is ploughing through the mantle, i.e. when the slab has sunken deep enough. Slab stretching (as discussed further in Section 4.2) acts to decrease the volume of slab sinking into the mantle which reduces the negative buoyancy forces. These effects explain increasing rollback velocities away from the slab edge and even roll-forward in some models, when mantle flow has become established.

In Fig. 4i, the slab is pinned at the boundary. Therefore toroidal flow is minimal and plays no role in shaping the slab edge. The shape 
a

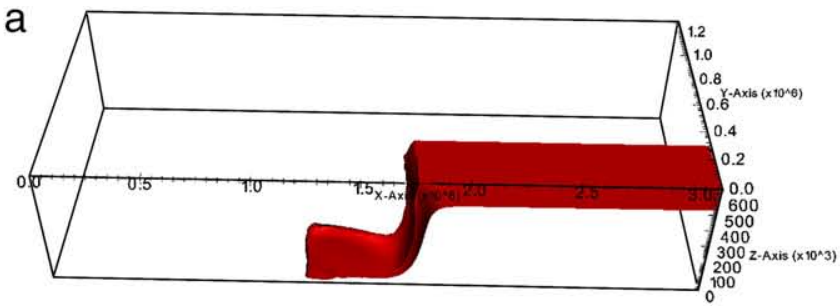

b

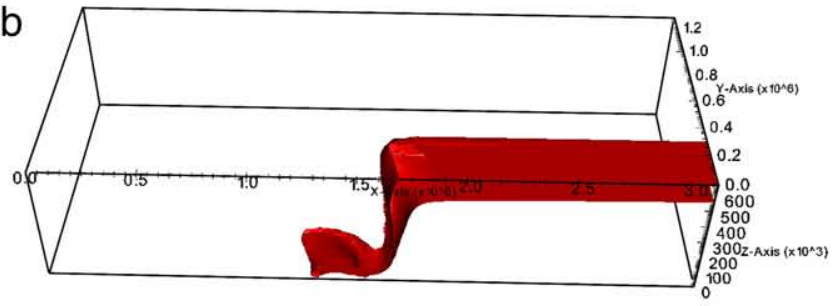

C

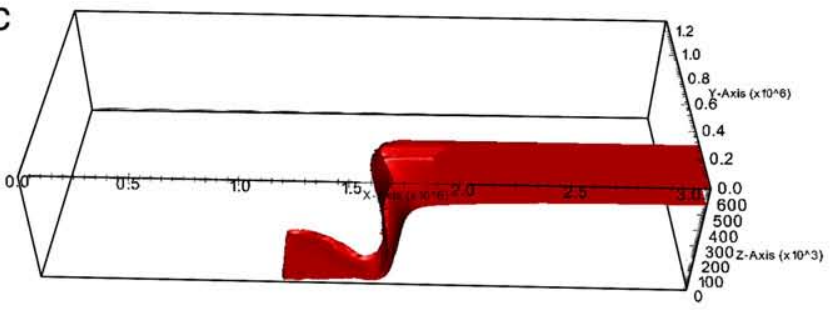

d

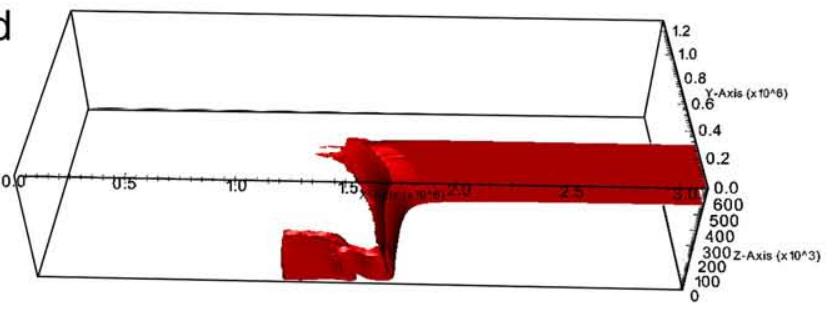

e

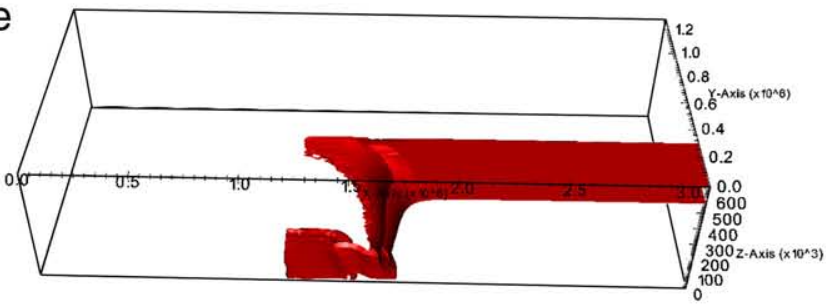

f

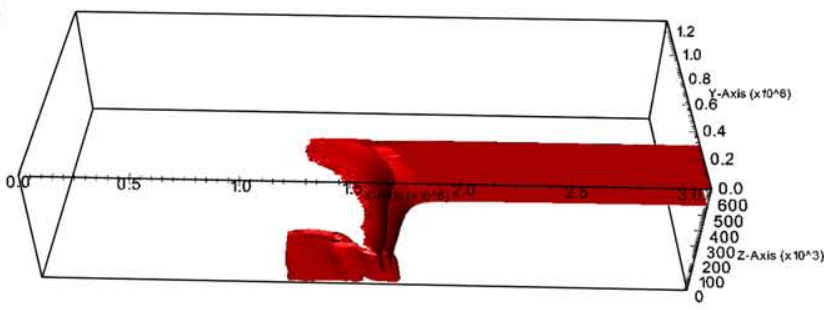

g

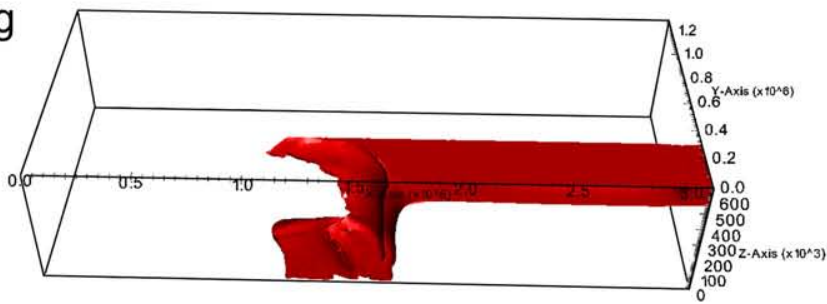

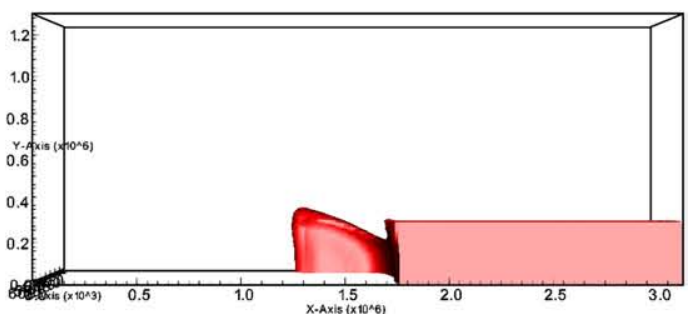
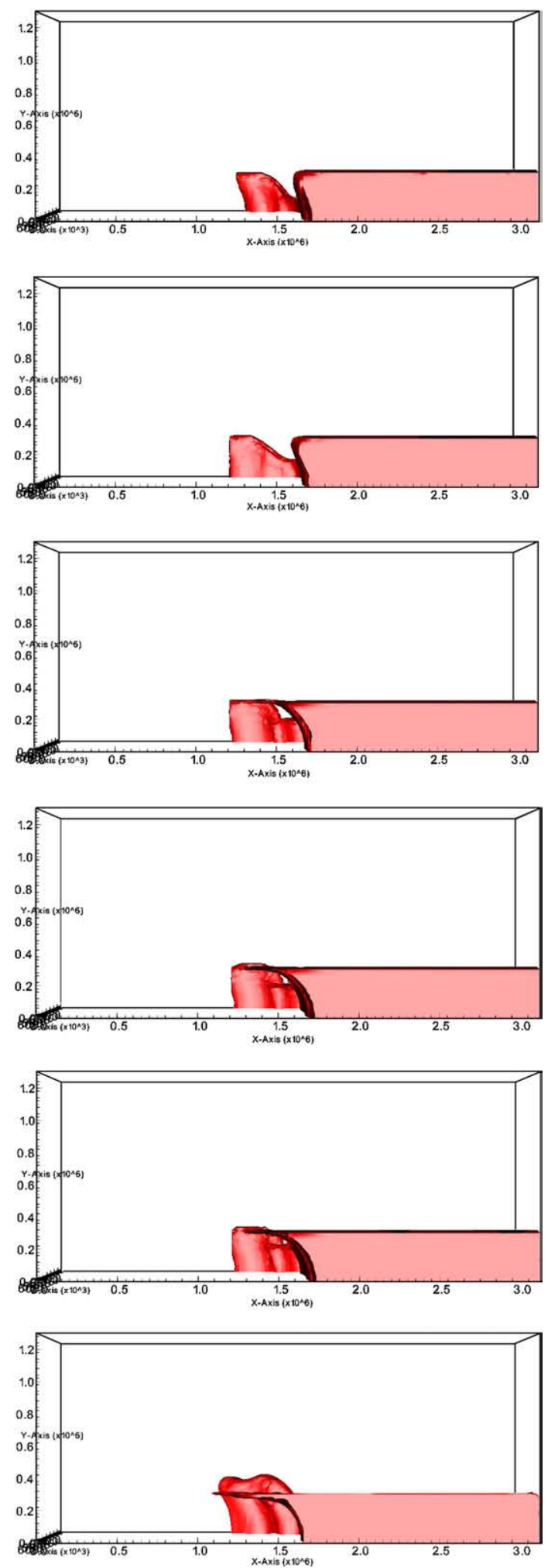


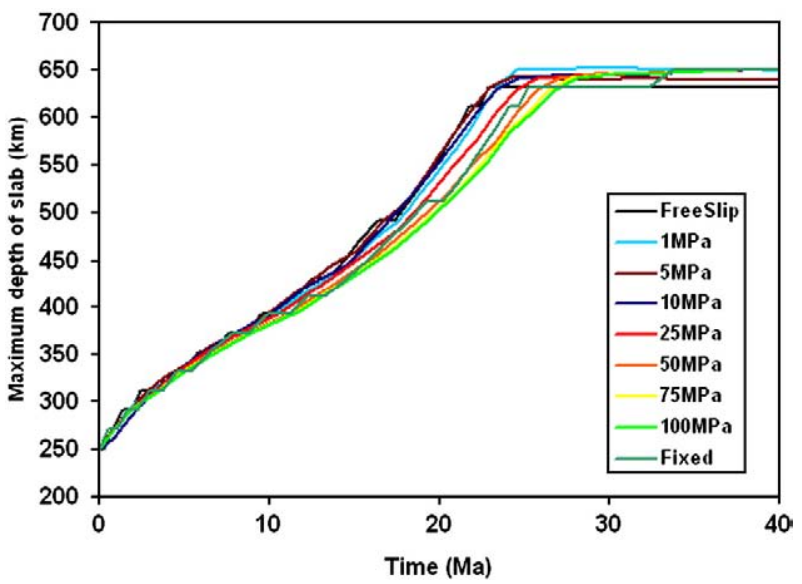

Fig. 7. Results show the maximum depth reached by the subducting slab below the freesurface against time for all simulations (the slab is initiated at a maximum depth of $250 \mathrm{~km}$ below the free-surface). The key for the graph is given in Table 2 .

of the hinge zone is still that of an arc, because rollback is least hindered in the centre of the slab.

In summary, results show that slab tearing with low yield strength promotes accelerated rates of subduction rollback while the arc shape remains relatively straight (Fig. 5a). Both effective rollback and arc curvature are obtained with higher values of yield strength (25$100 \mathrm{MPa}$; Fig. 5b), whereas boundaries with maximum resistance result in curvature at the central slab segment but no tearing (Fig. $5 \mathrm{c}$ ). Our results affirm earlier suggestions that interactions between subduction rollback and toroidal flow are important controls on arc curvature (Schellart and Lister, 2004; Stegman et al., 2006; Schellart et al., 2007). In addition, we recognize tear resistance as another controlling parameter for the dynamics of subduction zones. While for a free-slip boundary condition, the curvature of the slab is purely controlled by toroidal flow (Stegman et al., 2006), increasing the yield strength along the tear fault corresponds to settings in which the subducting slab is controlled more by the weak layer and less by the toroidal flow around the slab.

\subsection{Slab morphology}

We used the OpenGL software package VisIt (https://wci.llnl.gov/ codes/visit/) to visualize snapshots of the subducting lithosphere within the model domain as shown in Fig. 6 . The snapshots show the subducting lithosphere after rollback of the slab hinge to a maximum distance of $500 \mathrm{~km}$ (i.e. the slab hinge at the symmetry boundary reaches a distance of $1700 \mathrm{~km}$ in the model domain since it was initialised at a distance of $1200 \mathrm{~km}$ ). Results show that as the yield strength in the weak layer is increased, the curvature created by the hinge also increases (as shown in Fig. 4). However, Fig. 6 also shows that as the yield strength in the weak layer is increased, the subducting slab can become recumbently folded at the base of the domain. This is a consequence of the increasing resistance to slab rollback at the slab boundary as the yield strength in the weak layer is increased. As a result, the slab length increases by stretching without rollback being sufficiently fast to compensate. Slab stretching can be observed in Fig. 6b,c for yield strength of $1 \mathrm{MPa}$ and $5 \mathrm{MPa}$ in the weak layer, respectively. The subducting slab in Fig. $6 c$, which has the higher yield strength, experiences more stretching than the subducting slab in Fig. 6b. Fig. 6 also shows that as the yield strength in the weak layer is increased, the slab becomes more resistant to tearing and a thin a

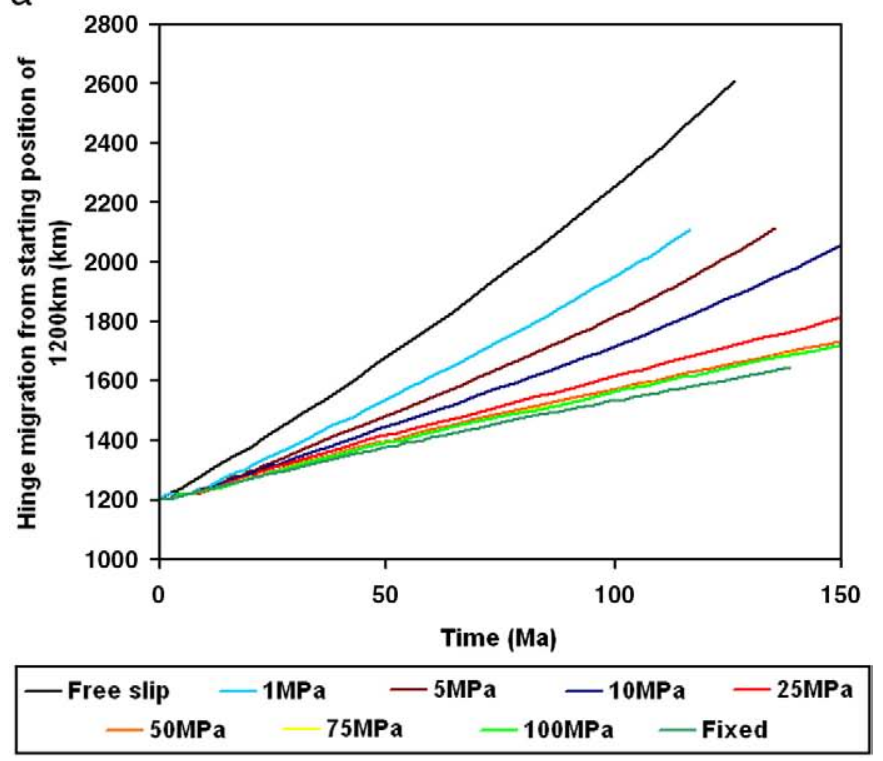

b

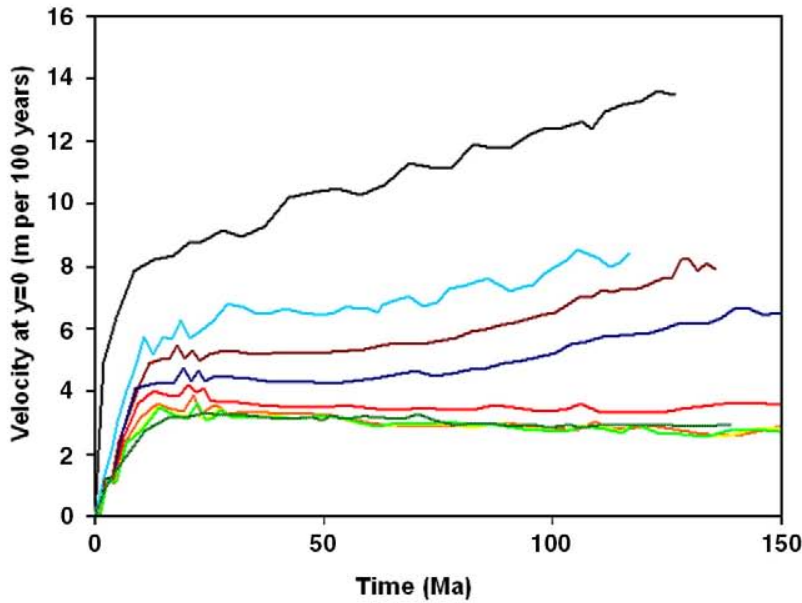

Fig. 8. (a) Results show hinge migration distance at the symmetry boundary from an initial distance of $1200 \mathrm{~km}$ against time for all simulations. The key for the graph is given in Table 2. All simulation have a yield strength of $100 \mathrm{MPa}$ for the plate and a density difference between plate and mantle of $\Delta \rho=69 \mathrm{~kg} \mathrm{~m}^{-3}$. (b) Results show slab rollback velocity at the symmetry boundary from an initial distance of $1200 \mathrm{~km}$ against time for all simulations. The key for the graph is given in Table 2. All simulations have a yield strength of $100 \mathrm{MPa}$ for the plate and a density difference between plate and mantle of $\Delta \rho=69 \mathrm{~kg} \mathrm{~m}^{-3}$.

layer of lithosphere can remain attached to the weak layer boundary, as shown in Fig. 6d-g.

As discussed in Section 4.1, the shape that the subducting hinge makes with the free-surface is partially controlled by the magnitude of the yield strength in the weak layer. Low yield strength can result in the slab edge experiencing the largest rollback rates. While higher yield strength in the weak zone can result in the slab remaining attached to the fixed slab, as well as slab stretching, necking and reduced negative buoyancy forces. 


\subsection{Maximum slab depth}

Fig. 7 shows the maximum depth of the slab at the symmetry boundary $(y=0)$ for simulations with varying yield strength values (simulations $0-8$ in Table 2). Results show that increasing tear resistance slows the sinking of the slab. A subducting slab with no tear resistance would reach the base of the model domain approximately 3 Myr earlier than the subducting slab with maximum tear resistance. This difference accounts for approximately $10 \%$ of the total time taken for the slab to reach the bottom of the domain.

Qualitatively, all simulations are characterized by similar behaviour (Fig. 7), suggesting that the dynamics of this diagnostic parameter (maximum depth of the subducting slab) is primarily controlled by the geometry of our model setup. Ultimately it is the combination of the competing forces: the negative buoyancy forces, mantle drag, resistance to bending at the surface and tear resistance at the slab edge that controls the sinking velocity. Resistance to bending at the slab hinge and tearing at the slab edge are approximately constant throughout a simulation. The negative buoyancy forces are proportional to the volume of lithosphere embedded in the mantle material above the bottom of the domain, whereas mantle drag is proportional to the area of the slab. We can therefore identify four stages of subduction dynamics. In stage 1 , the slab sinks rapidly and relatively uniformly, characterised by mainly poloidal flow and minimum mantle drag. During stage 2, induced toroidal to poloidal flow increases, the cross section of the slab increases and hence mantle drag increases. Consequently the sinking speed of the slab decreases. Stage 3 shows accelerated sinking of the slab due to the increasing volume to area ratio of the slab with lithospheric deformation dominated by slab negative buoyancy forces rather than mantle drag. The last stage (stage 4 ) corresponds to the interaction of the slab with the $660 \mathrm{~km}$ boundary.

\subsection{Hinge migration}

Fig. 8a shows the hinge location of the slab at the symmetry boundary $(y=0)$ for simulations, with varying yield strength values (simulations $0-8$ in Table 2 ). Results show that as the tear resistance is increased, the hinge rollback migrating speed is reduced, showing that hinge migration can be significantly affected by tear resistance. Comparing the simulation with a tearing yield resistance of $100 \mathrm{MPa}$ to the simulation with free-slip, the migration of the hinge at $y=0$ moves approximately one third of the distance for the same time-period.

Fig. $8 \mathrm{~b}$ shows the hinge migration velocity at the symmetry boundary $(y=0)$, which is arguably the most important kinematic parameter in subduction zones (Schellart et al., 2008). Our simulated subduction models have hinge migration velocities at the symmetry boundary $(y=0)$ of $2.5 \mathrm{~cm} /$ year-15.5 cm/year. These values are within the observed range of $-2.5 \mathrm{~cm} /$ year $-15.5 \mathrm{~cm} /$ year for comparable slab widths (Schellart et al., 2007). All our simulations show that the slab experiences accelerating hinge migration velocity until it interacts with the $660 \mathrm{~km}$ boundary. This is mainly due to the increasing negative buoyancy forces acting on the slab modulated by smaller effects, as discussed in the previous sections.

Once the slab interacts with the $660 \mathrm{~km}$ boundary, hinge rollback maintains a constant speed (for simulations with high yield strength values) or increases at a slower rate (for simulations with low yield strength values). Simulations in which hinge rollback continues to accelerate (after the slab has reached the $660 \mathrm{~km}$ boundary) correspond to simulations in which the slab edge $(280 \mathrm{~km}-300 \mathrm{~km})$ experiences the largest rollback rates (Fig. 4). Accelerating rollback without increasing the negative buoyancy forces suggests that preferential subduction at the edge (see Section 4.1) imposes an unbalanced force on the rest of the slab. Simulations with tear zone yield strengths less than $10 \mathrm{MPa}$ do not experience accelerating rollback at the slab edge during mature subduction, and consequently only constant rollback in the centre of the slab. Hinge migration is also approximately the same for all high yield strength models since tear resistance in these simulations plays only a minor role on central hinge migration.

We conclude that the negative buoyancy forces are the main control on hinge migration during incipient subduction, but tear resistance becomes significant for controlling the speed of subduction rollback. Our simulation results fall into two categories for mature subduction: accelerating rollback versus constant rollback. A low tear (yield) resistance in the weak layer permits continued acceleration of the subduction hinge, whereas a high tear (yield) resistance in the weak zone results in a constant rollback velocity.

We note that the oscillations for the hinge rollback velocity in Fig. $8 \mathrm{~b}$ are an artefact of how the velocity is calculated at the hinge. We perform a linear interpolation for the velocity based on the exact location of the hinge. However, since we cannot expect the velocity field between the node in the slab closest to the hinge and the adjacent node outside the slab to be linear, this results in the observed fluctuations in velocity.

\subsection{Trench width}

Trench width is an important parameter for subduction dynamics and has been extensively explored (Stegman et al., 2006; Schellart et al., 2007). These studies have shown that rollback velocity is
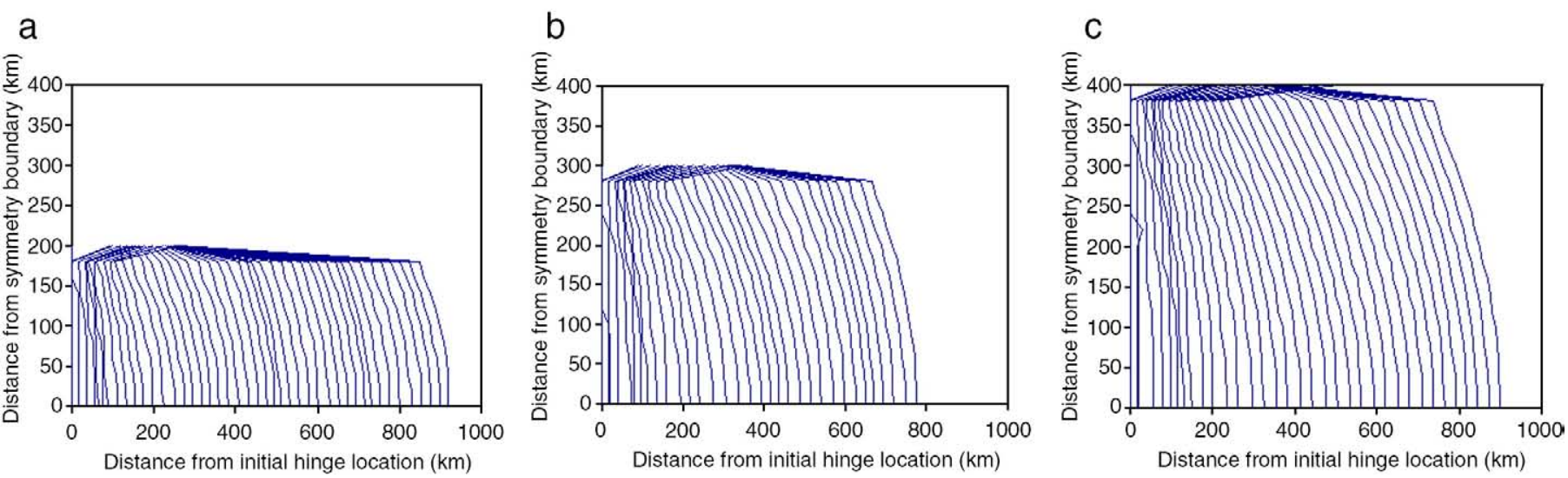

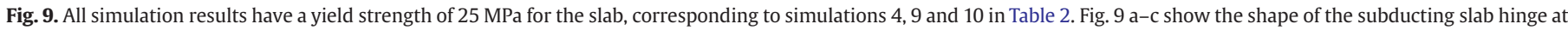

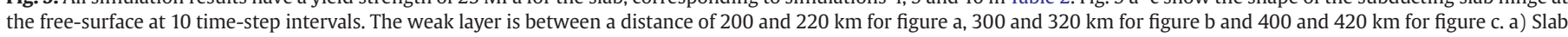
width $=400 \mathrm{~km}$. b) Slab width $=600 \mathrm{~km}$. c) Slab width $=800 \mathrm{~km}$. 
fastest approximately $300 \mathrm{~km}$ from the subduction edge, suggesting that induced toroidal flow is most significant at aiding rollback at that distance from the edge. However, it is the overall force balance which determines slab movement, and fast rollback velocities have also been observed/modelled in slab segments up to $900 \mathrm{~km}$ away from the next edge (Stegman et al., 2006, Schellart et al., 2007). This suggests a strong dependence on the tectonic setting/model configuration for rollback velocities. We performed simulations with different slab widths and constant tear resistances to observe the significance of our model setup and how it may influence the slab geometry.

All simulations shown in Fig. 9 have yield strength values of $25 \mathrm{MPa}$ in the weak zone, corresponding to simulations 4, 9 and 10 in

a

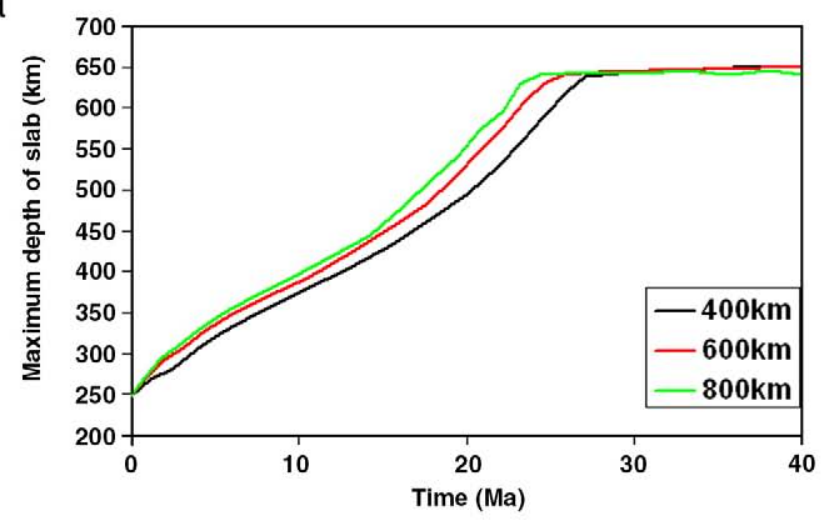

b

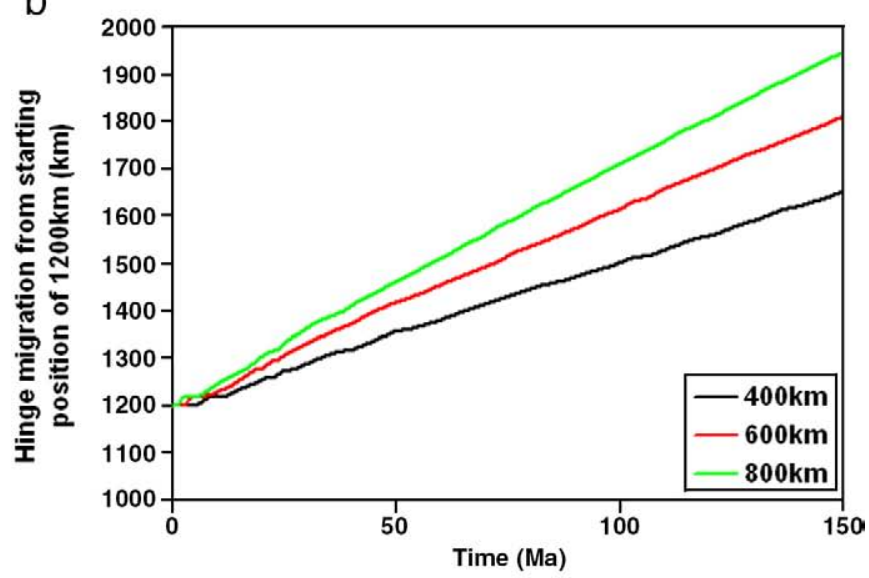

C

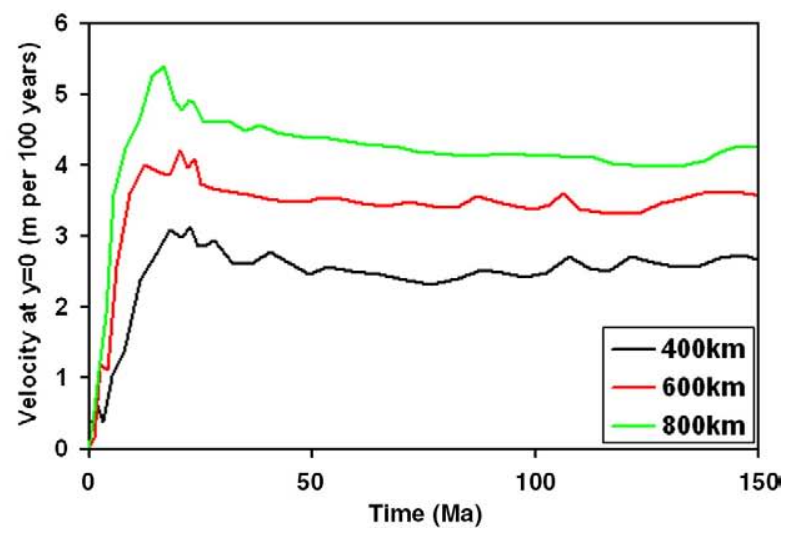

Fig. 10. All simulation results have a yield strength of $25 \mathrm{MPa}$ for the slab, corresponding to simulations 4, 9 and 10 in Table 2. a) Shows the maximum depth of the slab at $y=0$, the symmetry boundary. b) Shows the hinge migration location of the slab at $y=0$, the symmetry boundary. c) Shows the hinge migration velocity of the slab at $y=0$, the symmetry boundary.
Table 2. Fig. 9a-c shows the shape of the subducting slab hinge at the free-surface at 10 time-step intervals. As the width of the slab is increased, the hinge curvature also increases. This indicates that the effective scale of induced toroidal flow in our setup increases at least up to $400 \mathrm{~km}$. Note that as the width of the slab is increased, the weak layer experiences less rollback in this region.

Fig. 10a shows the maximum depth of the slab at $y=0$, the symmetry boundary, for subducting slabs with widths from $400 \mathrm{~km}$ to $800 \mathrm{~km}$. Our model results show qualitatively the same behaviour as discussed in Section 4.3. Increasing the width of the slab enhances the speed at which the slab descends into the mantle due to increased slab negative buoyancy forces (Fig. 10b). Lastly, Fig. 10c shows the hinge migration velocity of the slab at the symmetry boundary $(y=0)$. Hinge rollback is fastest for the widest slab, consistent with the previous diagnostic parameters.

Hence our setup acts to shift the point of maximum rollback (due to induced flow) further away from the edge.

\section{Discussion and conclusions}

We presented simulations of lithospheric subduction with tearing at the slab edges. Our results indicate that tear resistance is an important controlling parameter in the dynamics of subduction zones, in addition to interactions between subduction rollback and toroidal flow (Schellart and Lister, 2004; Stegman et al., 2006; Schellart et al., 2007).

Our simulation results follow an evolution in which the slab initially sinks rapidly and relatively uniformly since increasing slab negative buoyancy forces are the main control on hinge migration in incipient subduction. As the sinking slab begins to experience enhanced mantle drag, the rate of slab sinking begins to decrease. Following this, slab negative buoyancy forces can dominate over mantle drag, leading to accelerated sinking again. Lastly the slab interacts with the $660 \mathrm{~km}$ boundary.

Simulation results show that the curvature of the slab hinge is controlled by toroidal flow and the resistance experienced in the tear region. Slab tearing with low or zero yield strength results in a slab hinge shape that remains relatively straight, whereas increasing the yield strength within the tear region results in the curvature of the hinge becoming more prominent. Increasing the yield strength along the tear region corresponds to settings in which the subducting slab is controlled more by the weak layer and less by the toroidal flow around the slab. For a pinned boundary at the edge of the subducting slab, toroidal flow plays no role in the shape of the subducting slab, but the slab hinge shape produced is that of an arc. Hence, our simulations show that there are three inherent end-members controlling the slab hinge shape: slab-pinning, slab rollback controlled by tearing and slab rollback controlled by toroidal flow. Please note that our models are simplified with respect to real tectonic settings. Neglected features include mantle wind and lithospheric inhomogeneities, which also affect subduction. Visualised snapshots of the subducting lithosphere show how the geometry of the slab is influenced by the resistance in the weak layer. As the yield strength in the weak layer is increased, the subducting slab can become recumbently folded at the base of the domain. This is due to the slab length increasing due to stretching without rollback being sufficiently fast to compensate. Introducing a higher viscosity lower mantle region to the base of our domain is likely to affect the volume of lithosphere sinking into the lower mantle due to recumbent folding. As the yield strength in the weak layer is increased, slab stretching can result in reduced slab negative buoyant forces due to the slab thinning. In contrast, for low yield strengths in the weak layer, the largest rollback velocities can occur close to the slab edge due to the generation of a low viscosity layer at the slab edge.

Increasing the tear resistance at the edge of the slab acts to slow the sinking of the slab by up to $10 \%$. The migration velocity of subduction 
zones $200-400 \mathrm{~km}$ from the edge of the slab are in the range $-2.5 \mathrm{~cm} /$ year-15.5 cm/year (Schellart et al., 2008). This is comparable with our simulated values of $2.5 \mathrm{~cm} /$ year- $15.5 \mathrm{~cm} /$ year. Further, our simulation results fall into two categories for mature subduction: accelerating rollback versus constant rollback. It is the magnitude of tear resistance that controls hinge migration, with constant rollback maintained for tear zones with high resistance. However, for low or zero resistance in tear zones the slab can experience continuing accelerated rollback.

The simulations presented in this paper impose a no-slip boundary condition at a depth of $100 \mathrm{~km}$ below the domain free-surface, either side of the subducting slab. In reality, either side of the subducting slab will be neighboured by lithosphere. The lithosphere resists deformation through mantle drag, but it is not completely rigid. Therefore, our simulations act to minimise additional deformation induced by toroidal flow in this region, while subduction models by Stegman et al. (2006) consider the neighbouring lithosphere behaving as deformable mantle. The real natural behaviour is possibly somewhere in between.

For simplicity we imposed the location of the tear region in our simulations. However, in reality the location of the tear zone will be governed by the shear stresses acting on the slab, which is likely to be modified by the interaction of rollback, tear resistance at the fault, induced mantle flow and inhomogeneities in the lithosphere. All of these processes may result in tearing occurring away from the preferred propagation direction. In addition to this, our simulations can be considered as being somewhat artificial by imposing the same tearing resistance for either side of the subducting slab, which in nature is likely to be a rather unusual situation. Our modelling technique has been shown to be very powerful for this natural phenomenon. Future models will consider scenarios in which the tear resistance is different for the two tear zones, which could have significant implications for explaining trench rotation, such as that observed at the Tonga-Kermadec-Hikurangi subduction zone.

Our visco-plastic models lack the inclusion of a strong core which has shown to be important in acting as a stress-guide to maintain slab pull (Morra et al., 2006). By including a stress-guide in future models, the slab would exert a stronger backwards propagating hinge migration and larger slab pull.

\section{Acknowledgements}

AJH gratefully acknowledges support from the Australian Research Council Discovery grant DP0771377. KDG acknowledges support from the University of Queensland New Staff Grant Scheme, project 2005001475. GR acknowledges support from the University of Queensland through the project, "The development of lithospheric tear faults in convergent plate boundaries". We thank Patrice Rey for constructive comments. We would like to thank two anonymous reviewers for their constructive comments and improvements to this manuscript.

\section{Appendix A. Stokes flow past a sphere}

Stokes flow past a sphere is a solution for the frictional force, or drag force, exerted on spherical objects with very small Reynolds numbers in a continuous viscous fluid. Stokes' law is derived by

\section{Table A1}

Parameters used for falling sphere benchmark model presented in Appendix A.

\begin{tabular}{lll}
\hline Parameter & Symbol & Value \\
Density contrast between fluids & $\Delta \rho$ & $10 \mathrm{~kg} / \mathrm{m}^{3}$ \\
Radius of sphere & $a$ & $120 \mathrm{~m}$ \\
Height of domain & $h$ & $5400 \mathrm{~m}$ \\
Viscosity of fluid & $\eta_{\mathrm{f}}$ & $10^{10} \mathrm{~Pa} \mathrm{~s}$ \\
Viscosity of sphere & $\eta_{\mathrm{s}}$ & $10^{13} \mathrm{~Pa} \mathrm{~s}$ \\
Gravity & $g$ & $10 \mathrm{~m} / \mathrm{s}^{2}$ \\
\hline
\end{tabular}

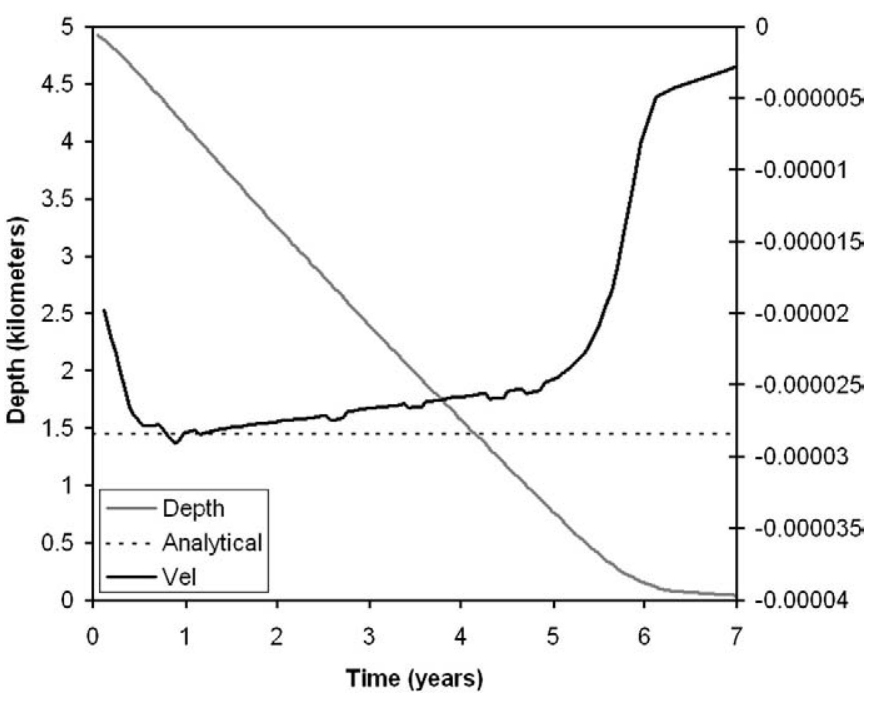

Fig. A1. Figure shows the velocity (black line) and depth (grey line) for a high viscosity sphere falling through a viscous fluid. Also shown is the analytical solution (dashed line) equal to $3.2 \times 10^{-5} \mathrm{~m} \mathrm{~s}^{-1}$.

solving the Stokes flow limit for small Reynolds numbers. With inertia neglected Stokes' flow is given by:

$\frac{\partial P_{i}}{\partial x_{j}}=\eta \rho\left(\frac{\partial v_{i}}{\partial x_{j}}+\frac{\partial v_{j}}{\partial x_{i}}\right)$

where $P$ is pressure, $v$ the velocity and $\eta$ the viscosity of the fluid. The pressure gradient is responsible for driving the flow by overcoming viscous resistance. Equating the drag and buoyant forces on the particle we can form an analytical solution for the free-falling terminal velocity, $v_{0}$ :

$v_{0}=\frac{2}{9} g a^{2} \frac{\Delta \rho}{\eta_{\mathrm{f}}}$

where $\Delta \rho$ is the density contrast between the fluids and $a$ the radius of the sphere. For our benchmark model we model a falling sphere as a high viscosity droplet with the parameter values given in Table A1. Using these parameters the maximum free-fall velocity of the sphere should equal $3.2 \times 10^{-5} \mathrm{~m} \mathrm{~s}^{-1}$. Results for a high viscosity sphere falling through a viscous fluid are shown in Fig. A1. Our simulation results start with the sphere velocity equal to zero, resulting in an initial period of acceleration. After a time of approximately 1 year, the falling sphere has reached its terminal velocity, equal to approximately $3.2 \times 10^{-5} \mathrm{~m} \mathrm{~s}^{-1}$, as shown by the dashed analytical line. The model domain was $5 \mathrm{~km}$ in length and from a time of one year onwards the falling sphere begins to experience the edge effects of the model domain, resulting in the sphere falling with decreasing velocity. The sphere reaches the base of the model domain after a period of approximately 6 years.

\section{Appendix B. Comparison to slab embedded in mantle models}

For completeness we simulate a subducting slab with a domain set-up as described in Fig. $4 \mathrm{~b}$, but without a fixed plate or a weak layer region, for comparison to previous studies (e.g. Stegman et al., 2006). Fig. A2a shows model results for the map-view shape of the subduction hinge for the simulation with free-slip at $y=300 \mathrm{~km}$. Fig. A2b shows results for the map-view shape of the subduction hinge for exactly the same model parameters as the results shown for Fig. A2a, except that this simulation has no fixed boundary condition at $y=300 \mathrm{~km}$. Results are shown at 10 time-step 
a

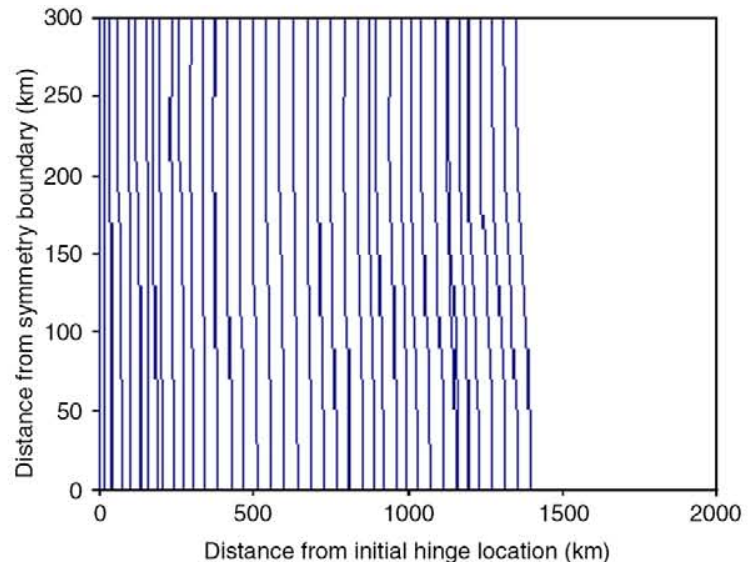

C

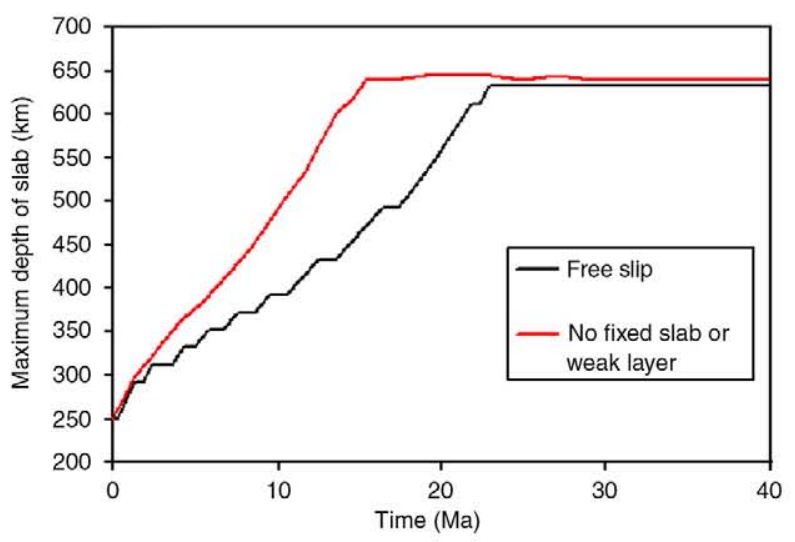

b

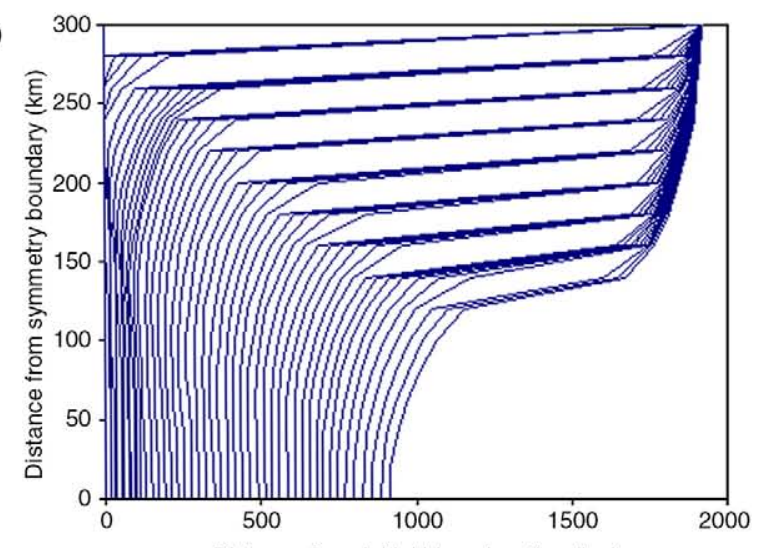

d

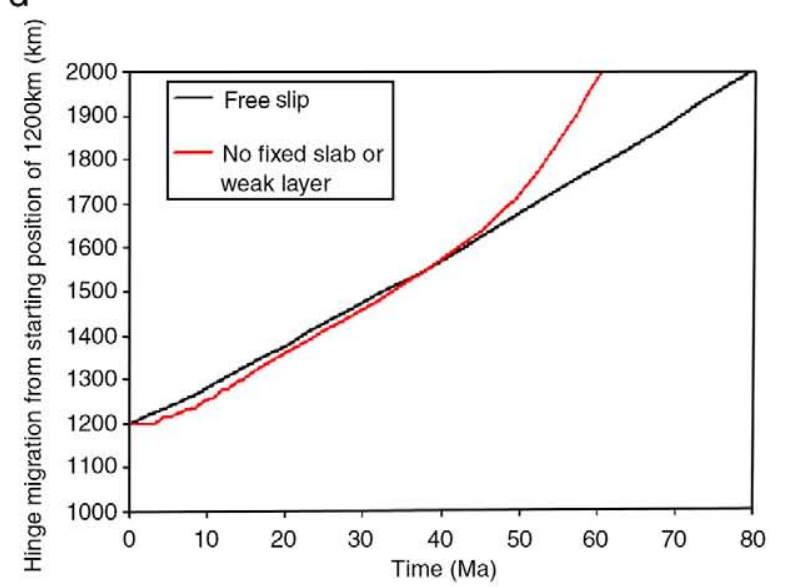

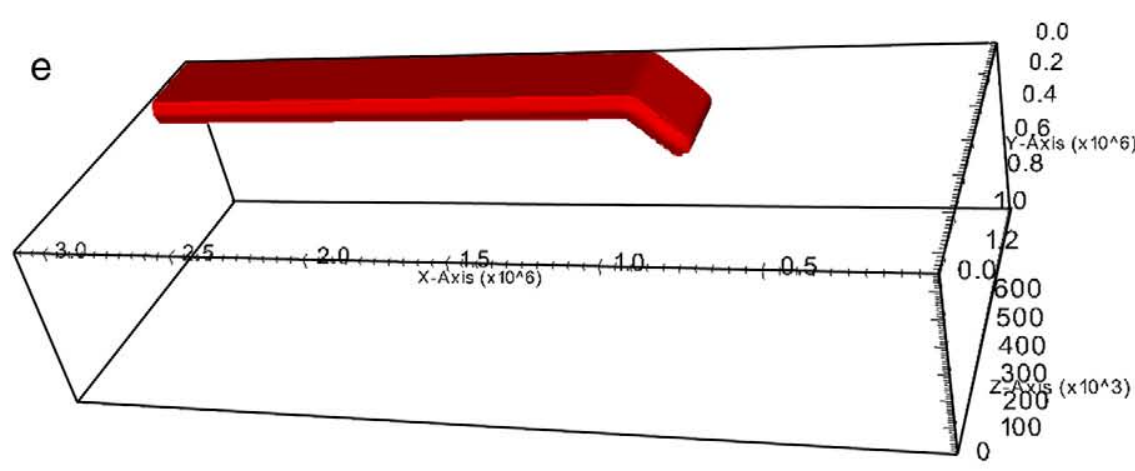

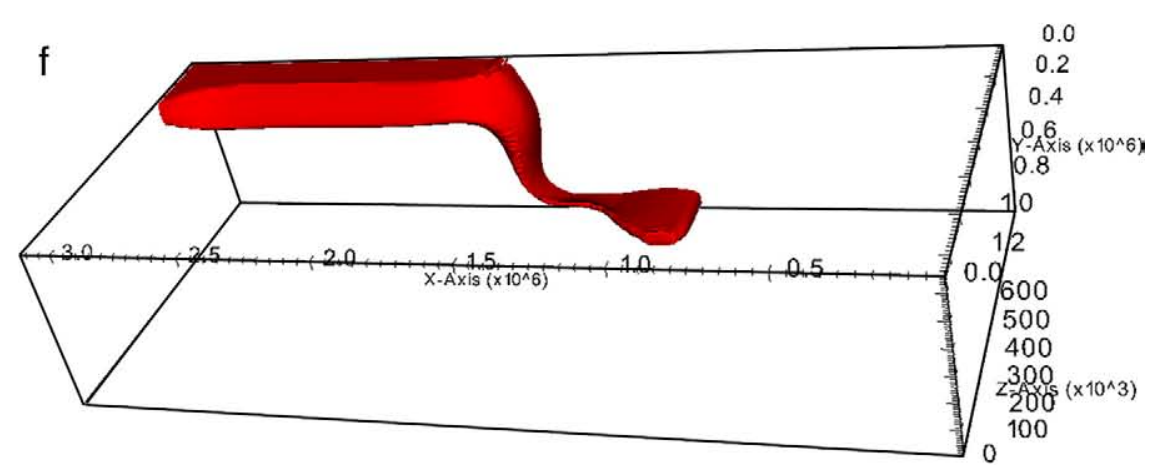

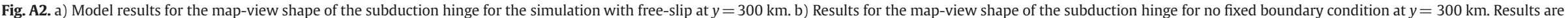

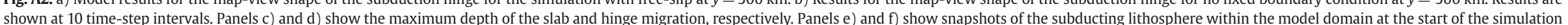
after a time of approximately $50 \mathrm{Ma}$, respectively. 
intervals and show the significance of the simulated boundary condition at the edge of the slab. Without a fixed boundary the slab edge is embedded into the mantle material, which flows around the slab during rollback, initially producing a more prominent arc shape until the edges of the slab begin to advance into the centre of the slab.

Fig. A2c and d show the maximum depth of the slab and hinge migration, respectively, for the simulations with a free-slip boundary condition and for the slab embedded in the mantle. These results show that the depth the slab reaches in time in enhanced when the slab is embedded within the mantle.

Fig. A2e and f show snapshots of the subducting lithosphere within the model domain, for the simulation with no fixed boundary condition at $y=300 \mathrm{~km}$, at the start of the simulation after a time of approximately $50 \mathrm{Ma}$, respectively. These snapshots show how the edge of the slab (as well as the end) subducts into the mantle.

\section{References}

Afonso, J.C., Ranalli, G., Fernàndez, M., 2007. Density structure and buoyancy of the oceanic lithosphere revisited. Geophysical Research Letters 34. doi:10.1029/ 2007GL029515 L10302.

Billen, M.I., Hirth, G., 2005. Newtonian versus non-Newtonian upper mantle viscosity: implications for subduction initiation. Geophysical Research Letters 32. doi:10.1029/2005GL023457 L19304.

Byerlee, J., 1968. Brittle-ductile transition in rocks. Journal of Geophysical Research 73 , 4741-4750.

Dewey, J.F., 1980. Episodicity, sequence, and style at convergent plate boundaries. Geological Association of Canada Special Paper 20, 553-573.

Dvorkin, J., Nur, A., Mavko, G., Ben-Avraham, Z., 1993. Narrow subducting slabs and the origin of backarc basins. Tectonophysics 227, 63-79.

Funiciello, F., Faccenna, C., Giardini, D., Regenauer-Lieb, K., 2003. Dynamics of retreating slabs: 2. Insights from three-dimensional laboratory experiments. Journal of Geophysical Research 108, 2207. doi:10.1029/2001JB000896.

Garfunkel, Z., Anderson, C.A., Schubert, G., 1986. Mantle circulation and the lateral migration of subducted slabs. Journal of Geophysical Research 91, 7205-7223.

Gordon, R.G., 2000. Diffuse oceanic plate boundaries: strain rates, vertically averaged rheology, and comparisons with narrow plate boundaries and stable plate interiors. In: Richards, M.A., Gordon, R., van der Hilst, R. (Eds.), The History and Dynamics of Global Plate Motions. InAmerican Geophysical Union, Washongton D.C. pp. 143-159.

Govers, R., Wortel, M.J.R., 2005. Lithosphere tearing at STEP faults: response to edges of subduction zones. Earth and Planetary Science Letters 236, 505-523.

Gross, L., Bourgouin, L., Hale, A.J., Mühlhaus, H.B., 2007. Interface modeling in incompressible media using level sets in Escript. Physics of the Earth and Planetary Interiors 163, 23-34.

Gurnis, M., Zhong, S., Toth, J., 2000. On the competing roles of fault reactivation and brittle failure in generating plate tectonics from mantle convection. In: Richards, $\mathrm{M}$. A., Gordon, R., van der Hilst, R. (Eds.), The History and Dynamics of Global Plate Motions. InAmerican Geophysical Union, Washongton D.C., pp. 73-94.

Hale, A.J., Bourgouin, L., Mühlhaus, H.B., 2007. Using the level set method to model endogenous lava dome growth. Journal of Geophysical Research 112, B03213. doi:10.1029/2006JB004445.

Kaus, B.J.P., Podladchikov, Y.Y., 2006. Initiation of localized shear zones in viscoelastoplastic rocks. Journal of Geophysical Research 111. doi:10.1029/2005JB003652 B04412.

Kohlstedt, D.L., Evans, B., Mackwell, S.J., 1995. Strength of the lithosphere: constraints imposed by laboratory experiments. Journal of Geophysical Research 100,17,587-17,602.

Lachenbruch, A.H., Sass, J.H., 1991. Heat flow from the Cajon Pass, fault strength, and tectonic implications. Journal of Geophysical Research 97, 4995-5015.

Lallemand, S., Heuret, A., Boutelier, D., 2005. On the relationships between slab dip, backarc stress, upper plate absolute motion, and crustal nature in subduction zones. Geochemistry Geophysics Geosystems 6. doi:10.1029/2005GC000917 Q09006.
Mitrovica, J.X., Forte, A.M., 2004. A new inference of mantle viscosity based upon joint inversion of convection and glacial isostatic adjustment data. Earth and Planetary Science Letters 225, 177-189.

Moresi, L., Solomatov, V., 1998. Mantle convection with a brittle lithosphere: thoughts on the global tectonic styles of the Earth and Venus. Geophysical Journal International 133, 669-682.

Morra, G., Regenauer-Lieb, K., Giardini, D., 2006. Curvature of oceanic arcs. Geology 34 $877-880$.

Osher, S., Sethian, J.A., 1988. Fronts propagating with curvature dependent speed: algorithms based on Hamilton-Jacobi formulations. Journal of Computational Physics 79, 12-49.

OzBench, M., Regenauer-Lieb, K., Stegman, D.R., Morra, G., Farrington, R., Hale, A., May, D.A., Freeman, J., Bourgouin, L., Mühlhaus, H., Moresi, L., 2008. A model comparison study of large-scale mantle-lithosphere dynamics driven by subduction. Physics of the Earth and Planetary Interiors 171, 224-234.

Piromallo, C., Becker, T.W., Funiciello, F., Faccenna, C., 2006. Three-dimensional instantaneous mantle flow induced by subduction. Geophysical Research Letters 33. doi:10.1029/2005GL025390 L08304.

Regenauer-Lieb, K., Yuen, D.A., Branlund, J., 2001. The initiation of subduction: criticality by addition of water? Science $294,278-580$.

Regenauer-Lieb, K., Weinberg, R.F., Rosenbaum, G., 2006. The effect of energy feedbacks on continental strength. Nature 442, 67-70.

Regenauer-Lieb, K., Rosenbaum, G., Weinberg, R.F., 2008. Strain localisation and weakening of the lithosphere during extension. Tectonophysics 458, 96-104.

Rosenbaum, G., Gasparon, M., Lucente, F.P., Peccerillo, A., Miller, M.S., 2008. Kinematics of slab tear faults during subduction segmentation and implications for Italian magmatism. Tectonics 27. doi:10.1029/2007TC002143 TC2008.

Royden, L.H., 1993. Evolution of retreating subduction boundaries formed during continental collision. Tectonics 12, 629-638.

Royden, L.H., Husson, L., 2006. Trench motion, slab geometry and viscous stresses in subduction systems. Geophysical Journal International 167, 881-905.

Schellart, W.P., 2004a. Kinematics of subduction and subduction-induced flow in the upper mantle. Journal of Geophysical Research 109. doi:10.1029/2004JB002970 B07401.

Schellart, W.P., 2004b. Quantifying the net slab pull force as a driving mechanism for plate tectonics. Geophysical Research Letters 31. doi:10.1029/2004GL019528 L07611.

Schellart, W.P., 2008. Subduction zone trench migration: slab driven or overridingplate-driven? Physics of the Earth and Planetary Interiors 170, 73-88.

Schellart, W.P., Lister, G.S., 2004. Tectonic models for the formation of arc-shaped convergent zones and backarc basins. In: Sussman, A., Weil, A. (Eds.), Orogenic Curvature: Integrating Paleomagnetic and Structural Analyses: Geological Society of America Special Paper, pp. 237-258.

Schellart, W.P., Freeman, J., Stegman, D.R., Moresi, L., May, D., 2007. Evolution and diversity of subduction zones controlled by slab width. Nature 446, 308-311.

Schellart, W.P., Stegman, D.R., Freeman, J., 2008. Global trench migration velocities and slab migration induced upper mantle volume fluxes: constraints to find an Earth reference frame based on minimizing viscous dissipation. Earth-Science Reviews 88, 118-144.

Schubert, G., Turcotte, D., Olson, P., 2001. Mantle Convection in the Earth and Planets. Cambridge University Press, Cambridge.

Steffen, H., Kaufmann, G., 2005. Glacial isostatic adjustment of Scandinavia and northwestern Europe and the radial viscosity structure of the Earth's mantle. Geophysical Journal International 163, 801-812.

Stegman, D.R., Freeman, J., Schellart, W.P., Moresi, L., May, D., 2006. Influence of trench width on subduction hinge retreat rates in 3-D models of slab rollback. Geochemistry Geophysics Geosystems 7. doi:10.1029/2005GC001056 Q03012.

Steinberger, B., Calderwood, A.R., 2006. Models of large-scale viscous flow in the Earth's mantle with constraints from mineral physics and surface observations. Geophysical Journal International 167, 1461-1481.

Tackley, P., 2000a. Self-consistent generation of tectonic plates in time-dependent, threedimensional mantle convection simulations, 1. Pseudoplastic yielding. Geochemistry Geophysics Geosystems 1. doi:10.1029/2000GC000036.

Tackley, P.J., 2000b. Mantle convection and plate tectonics: toward an integrated physical and chemical theory. Science 288, 2002-2007.

Zehnder, A.T., 2006. Lecture Notes on Fracture Mechanics. Cornell University, Dept. of Theoretical and Applied Mechanics, Ithaca, NY. http://hdl.handle.net/1813/3075. 